\title{
Functional rejuvenation of aged neural stem cells by Plagl2 and anti-Dyrk1a activity
}

\author{
Takashi Kaise, ${ }^{1,2,5}$ Masahiro Fukui, ${ }^{1,2}$ Risa Sueda, ${ }^{1,3}$ Wenhui Piao, ${ }^{1,3}$ Mayumi Yamada, ${ }^{1,3,4}$ \\ Taeko Kobayashi, ${ }^{1,2,3}$ Itaru Imayoshi, ${ }^{1,3,4}$ and Ryoichiro Kageyama ${ }^{1,2,3,4,5}$ \\ ${ }^{1}$ Institute for Frontier Life and Medical Sciences, Kyoto University, Kyoto 606-8507, Japan; ${ }^{2}$ Graduate School of Medicine, Kyoto \\ University, Kyoto 606-8501, Japan; ${ }^{3}$ Research Center for Dynamic Living Systems, Graduate School of Biostudies, Kyoto \\ University, Kyoto 606-8501, Japan; ${ }^{4}$ Institute for Integrated Cell-Material Sciences, Kyoto University, Kyoto 606-8501, Japan
}

The regenerative potential of neural stem cells (NSCs) declines during aging, leading to cognitive dysfunctions. This decline involves up-regulation of senescence-associated genes, but inactivation of such genes failed to reverse aging of hippocampal NSCs. Because many genes are up-regulated or down-regulated during aging, manipulation of single genes would be insufficient to reverse aging. Here we searched for a gene combination that can rejuvenate NSCs in the aged mouse brain from nuclear factors differentially expressed between embryonic and adult NSCs and their modulators. We found that a combination of inducing the zinc finger transcription factor gene Plagl2 and inhibiting Dyrk1a, a gene associated with Down syndrome (a genetic disorder known to accelerate aging), rejuvenated aged hippocampal NSCs, which already lost proliferative and neurogenic potential. Such rejuvenated NSCs proliferated and produced new neurons continuously at the level observed in juvenile hippocampi, leading to improved cognition. Epigenome, transcriptome, and live-imaging analyses indicated that this gene combination induces up-regulation of embryo-associated genes and down-regulation of age-associated genes by changing their chromatin accessibility, thereby rejuvenating aged dormant NSCs to function like juvenile active NSCs. Thus, aging of NSCs can be reversed to induce functional neurogenesis continuously, offering a way to treat age-related neurological disorders.

[Keywords: adult neurogenesis; aged brain; Ascl1; ATAC-seq; ChIP-seq; Dyrk1a; lentivirus; mouse; neural stem cell; Plag12]

Supplemental material is available for this article.

Received September 4, 2021; revised version accepted November 29, 2021.

Neurogenesis occurs primarily in two regions of the adult mammalian brain: the subgranular zone of the hippocampal dentate gyrus (DG-SGZ) and the subventricular zone of the lateral ventricles (LV-SVZ) (Lepousez et al. 2015; Gonçalves et al. 2016; Miller and Sahay 2019|. Neural stem cells (NSCs) present in these two regions are mostly quiescent but occasionally become activated to produce new neurons, which subsequently integrate into pre-existing neural circuits and play an important role in learning and memory (Seri et al. 2001; Lagace et al. 2007; Imayoshi et al. 2008; Gage and Temple 2013). However, neurogenesis in the adult brain declines with age, which may lead to cognitive dysfunction. In the hippocampus of the aged mouse brain, not only the number of quiescent NSCs but also their activation rate and/or neurogenic po-

\footnotetext{
${ }^{5}$ Present address: RIKEN Center for Brain Science, Wako 351-0198, Japan. Corresponding author: ryoichiro.kageyama@riken.jp

Article published online ahead of print. Article and publication date are online at http://www.genesdev.org/cgi/doi/10.1101/gad.349000.121. Freely available online through the Genes \& Development Open Access option.
}

tential are significantly reduced compared with young NSCs (Lugert et al. 2010; Encinas et al. 2011; Bast et al. 2018). Although activation of neurogenesis can ameliorate age-related cognitive dysfunctions and neurodegenerative disorders (Benraiss et al. 2013; Choi et al. 2018; DíazMoreno et al. 2018), current methods activate NSCs only transiently and lead to exhaustion of NSCs, thereby terminating neurogenesis prematurely (Ehm et al. 2010; Imayoshi et al. 2010; Mira et al. 2010; Bonaguidi et al. 2011; Encinas et al. 2011; Engler et al. 2018; Sueda et al. 2019; Zhang et al. 2019|. It remains to be analyzed whether NSCs can be activated for an extended period of time, particularly in the aged brain.

To decipher the molecular mechanism by which the active versus quiescent state of NSCs is controlled in the adult brain, intensive studies including transcriptomic

(C) 2022 Kaise et al. This article, published in Genes \& Development, is available under a Creative Commons License (Attribution-NonCommercial 4.0 International), as described at http://creativecommons.org/licenses/by-nc/4.0/. 
analyses have been performed (Llorens-Bobadilla et al. 2015; Shin et al. 2015; Artegiani et al. 2017; Dulken et al. 2017; Hochgerner et al. 2018; Urbán et al. 2019). These studies as well as previous ones showed that the activation of Wnt signaling, inhibition of Bmp signaling, induction of Ascl1 oscillations, or lysosomal activation increases the number of active NSCs (Lie et al. 2005; Mira et al. 2010; Benraiss et al. 2013; Jang et al. 2013; Seib et al. 2013; Díaz-Moreno et al. 2018; Leeman et al. 2018; Kalamakis et al. 2019; Sueda et al. 2019). Notch1 signaling is also required for maintenance of active NSCs, although Notch2 signaling induces quiescence (Nyfeler et al. 2005; Ables et al. 2010; Ehm et al. 2010; Imayoshi et al. 2010; Basak et al. 2012; Engler et al. 2018). By modulating these signaling pathways, NSCs can be activated to produce some neurons in the young to middle-aged brain; however, this effect is limited in the aged brain $(>18 \mathrm{mo}$ of age for mice) (Berdugo-Vega et al. 2020). Therefore, to restore active neurogenesis, it is important to rejuvenate both the proliferative and neurogenic potential of dormant NSCs.

To rejuvenate aged NSCs, many attempts to change cellintrinsic properties have been performed. The expression of the cyclin-dependent kinase inhibitor $\mathrm{p} 16^{\mathrm{INK} 4 \mathrm{a}}$ linked to senescence increases during aging, thereby decreasing regenerative functions of NSCs (Molofsky et al. 2006). However, inactivation of $\mathrm{p} 16^{\mathrm{INK} 4 \mathrm{a}}$ failed to rejuvenate aged NSCs in the hippocampus (Molofsky et al. 2006), and therefore it is not clear whether NSCs can be functionally rejuvenated in the aged brain. It was previously shown that the proneural gene Ascl1 is absolutely required for activation of NSCs and production of new neurons in the adult brain (Andersen et al. 2014), and that Id4 promotes the degradation of Ascll protein, leading to quiescence in NSCs (Blomfield et al. 2019; Zhang et al. 2019). Indeed, inactivation of Id4 increases Ascll expression and activates NSCs in the adult hippocampal dentate gyrus; however, the effect on neurogenesis does not continue, probably due to compensation by other Id proteins (Blomfield et al. 2019). It was shown that oscillatory expression of Ascll is important for efficient proliferation of NSCs (Imayoshi et al. 2013), and that induction of Ascll oscillations can activate NSCs to proliferate and produce new neurons in the adult brain (Sueda et al. 2019). However, this activation is transient, and the effect on neurogenesis is limited (Sueda et al. 2019), suggesting that adult/aged NSCs are resistant to proliferation. Overexpression of the cell cycle regulators Cdk4 and cyclinD1 is able to activate proliferation of NSCs (Artegiani et al. 2011), but the effect on neurogenesis is also limited in the aged brain, probably because aged NSCs lose neurogenic potential (BerdugoVega et al. 2020). Therefore, despite all these intensive efforts, the long-term robust activation or rejuvenation of the proliferative and neurogenic potential of NSCs has not been achieved in the aged brain.

Here, to rejuvenate aged dormant NSCs, we sought to change their intrinsic properties and searched for the genes that enhance neurogenesis from those differentially expressed between embryonic and adult NSCs. We found that inducing Plagl2 and anti-Dyrk1a activity rejuvenates NSCs to proliferate and produce new neurons continuous- ly in the aged brain, thereby ameliorating age-related learning and memory deficits. We further analyzed the mechanism of how this treatment rejuvenates dormant NSCs and found that this activation results from up-regulation of key genes, such as Ascl1, whose chromatin structures become less accessible during aging.

\section{Results \\ Screening for NSC-activating genes}

To rejuvenate the proliferative and neurogenic potential of aged NSCs, we reasoned that the activity of multiple genes would need to be changed. As the majority of adult NSCs are quiescent, we compared the transcriptomes (DDBJ BioProject accession no. PRJDB9010) of G1/G0 NSCs from the ganglionic eminence and dorsal cortex of E14 mouse embryos with those of NSCs from the LV-SVZ and DGSGZ of 2- to 3-mo-old mice to identify differentially expressed nuclear factors and their known modulators. We first focused on the top 80 nuclear factor genes expressed at a high level in embryos ("embryonic-high") and examined their activity in NSC cultures. Each gene was overexpressed by using the Tet-ON system in NSC cultures, which were maintained in a quiescent state $\left(\mathrm{EdU}^{-}\right)$by bFGF and BMP (Fig. 1A; Supplemental Fig. S1A,B; Mira et al. 2010; Martynoga et al. 2013; Sueda et al. 2019). The proportions of EdU-incorporating proliferating cells were measured $2 \mathrm{~d}$ after doxycycline treatment to identify genes that can activate the proliferation of cultured NSCs (Supplemental Fig. S1B; Supplemental Table S1). Among the tested genes, Gsx2, Dmrt3, Cdk4, Plag12, Sox21, Asc11, Tgif2, Plag11, and Hmga2 induced the efficient activation of quiescent NSC cultures (Supplemental Fig. S1C,D), and they were tested further in vivo. These nine genes were cloned individually together with mCherry into a lentivirus under the control of the Hes5 promoter (Supplemental Fig. S1E), which directs NSC- and astrocyte-specific expression (Lugert et al. 2010; Sueda et al. 2019). Each lentivirus was injected into the hippocampal dentate gyrus of 6 mo-old mice, and brain sections were examined $1 \mathrm{wk}$ later (Fig. 1A; Supplemental Fig. S1F). Cdk4 was overexpressed with cyclin D1 (D1K4) (Supplemental Fig. S1G), because this combination reportedly activates NSCs in the adult brain (Artegiani et al. 2011). Among the tested genes, Plag12 most efficiently increased the number of $\mathrm{MCM}^{+}$ proliferating cells (most likely, active NSCs and intermediate progenitor cells [IPCs]) in the hippocampal dentate gyrus of 6-mo-old mice compared with the control(Supplemental Fig. S1G). The combination of Plag12 with Plag11, Hmga2, Sox21, Dmrt3, Gsx2, or Ascl1 did not significantly increase the number of $\mathrm{MCM}^{+}$or $\mathrm{DCX}^{+}$cells (data not shown).

We next performed knockdown of nuclear factor genes expressed at a high level in adult NSCs ("adult-high") and their modulators by introducing siRNA targeting these genes in quiescent NSC cultures to identify those that could activate the proliferation of NSCs (Fig. 1A; Supplemental Fig. S2A). Among 124 genes tested in knockdown screening in vitro, we selected 11 genes, Nr4a1, Stat6, 
A

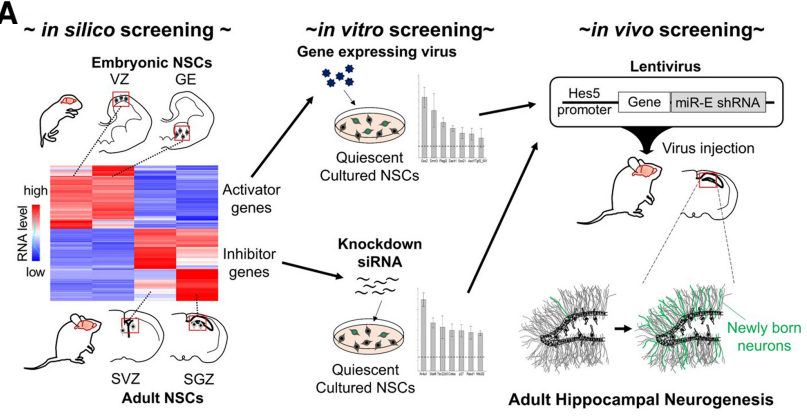

C

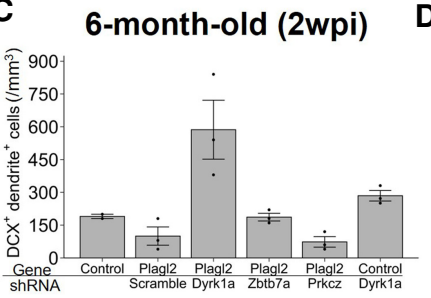

$\mathbf{E}$

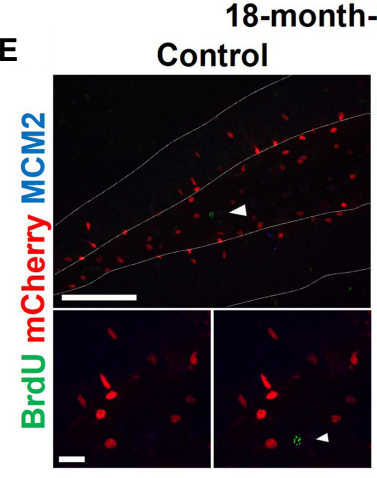
18-mol

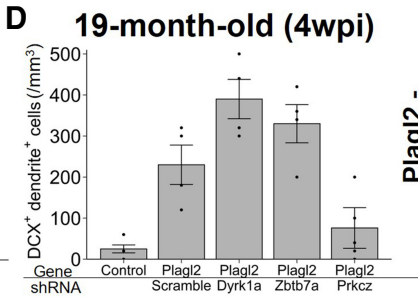

$\mathbf{F}$
B
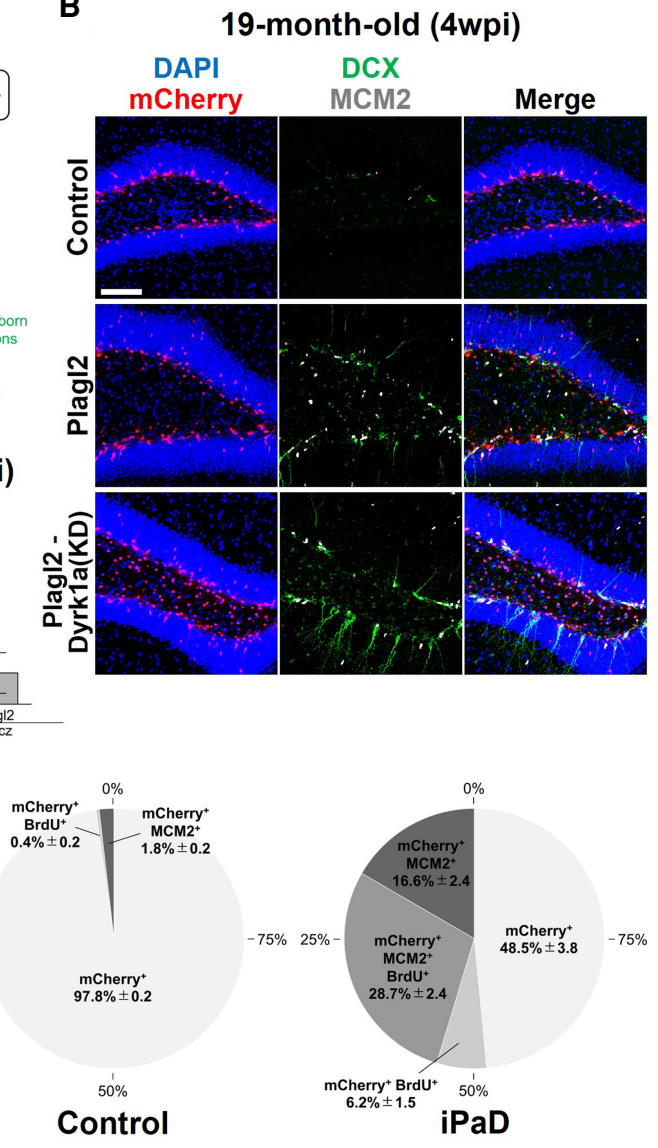

H $\begin{array}{ll}\text { 19-month-old (4wpi) } \\ \text { iPaD } & \text { BrdU DCX mCherry }\end{array}$

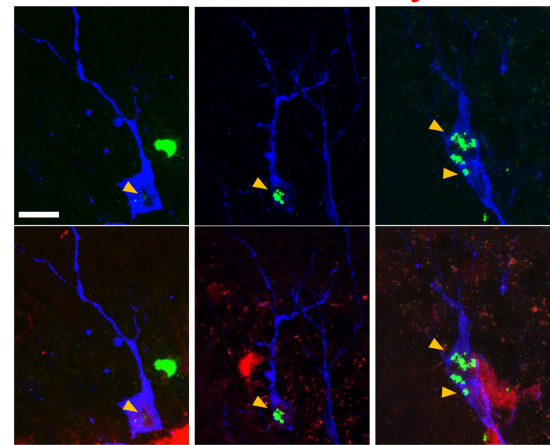

Figure 1. Screening for NSC-activating genes and analysis of the iPaD lentivirus. $(A)$ Strategy for NSC-activating gene screening. Genes involved in in vitro NSC activation were searched for by lentivirus-mediated overexpression or siRNA knockdown. Top genes were introduced into the hippocampal dentate gyrus of 6- or 18-mo-old mice using lentivirus, and brain sections were examined. (B) Control lentivirus, lentivirus inducing Plag12 expression, or lentivirus inducing Plagl2 expression and Dyrk1a knockdown (KD) was injected into the hippocampal dentate gyrus of 18-mo-old mice, and at $4 \mathrm{wk}$ postinfection (wpi; at 19 mo of age), the hippocampal dentate gyrus was examined immunohistochemically. Virus-infected cells were mCherry ${ }^{+} .(C, D)$ Quantification of $\mathrm{DCX}^{+}$dendrite ${ }^{+}$immature neuron formation in the hippocampal dentate gyrus of 6-mo-old mice at 2wpi $(C ; n=3)$ and 19-mo-old mice at 4 wpi $(D ; n=4)$. The upper and lower names along the horizontal axis indicate overexpressed and knockdown genes, respectively. $(E, G, H)$ Control or iPaD lentivirus was injected into the hippocampal dentate gyrus of 18-mo-old mice, and 2 or 4 wk later, the hippocampal dentate gyrus was examined immunohistochemically. Yellow arrowheads indicate virus-infected mitotic cells $\left(E ;\right.$ mCherry $\left.{ }^{+} \mathrm{BrdU}^{+} \mathrm{MCM}^{+}\right)$, active NSCs $(G$; mCherry $\left.{ }^{+} \mathrm{BrdU}^{+} \mathrm{GFAP}^{+} \mathrm{Sox}^{+}\right)$, and immature neurons $\left(H\right.$; three examples of mCherry ${ }^{+} \mathrm{BrdU}^{+} \mathrm{DCX}^{+}$dendrite ${ }^{+}$cells $)$, while white arrowheads indicate mCherry ${ }^{-} \mathrm{BrdU}^{+}$(non-virus-infected) cells. $(F)$ Quantification of quiescent NSCs $\left(\mathrm{MCM}^{-}\right)$and active NSCs or IPCs $\left(\mathrm{MCM}^{+}\right.$or BrdU-incorporating) in the hippocampal dentate gyrus at 2 wk after control and iPaD lentivirus injection of 18-mo-old mice. BrdU was administered intraperitoneally for $7 \mathrm{~d}$ until sacrifice. At least three samples were examined for each condition. Each value represents the mean \pm SEM. Scale bars: $B, 50 \mu \mathrm{m} ; E, G, H, 20 \mu \mathrm{m}$. 
Cidea, Tsc22d3, Rasd1, Cdkn1, Nfe212, Zbtb7a, Dusp22, Prkcz, and Dyrk1a, whose knockdown efficiently activated quiescent NSC cultures (Supplemental Fig. S2B-D; Supplemental Table S2). The expression of miR-E backbone shRNA (Fellmann et al. 2013) for each gene was induced in vivo together with Plagl2 and mCherry expression under the control of the Hes 5 promoter by using a lentivirus (Fig. 1A; Supplemental Fig. S2E). Each lentivirus was injected into the hippocampal dentate gyrus of 6- and 18- or 20-mo-old mice, and brain sections were examined 2 or 4 wk later (Fig. 1A; Supplemental Fig. S2G-J). Among them, Cdkn1a, Prkcz, and Dyrk1a shRNA similarly increased the number of $\mathrm{MCM}^{+}$active NSCs/IPCs in these mice (Supplemental Fig. S2G-J), but Dyrk1a shRNA also more efficiently increased the number of $\mathrm{DCX}^{+}$; dendrite $^{+}$cells than others in both 6- and 19-moold $(18 \mathrm{mo}+4 \mathrm{wk})$ mice (Fig. 1B-D). Compared with this combination, Dyrk1a knockdown alone did not effectively increase $\mathrm{MCM}^{+}$or $\mathrm{DCX}^{+}$; dendrite ${ }^{+}$cells (Fig. 1C; Supplemental Fig. S2I). These data indicated that the combination of overexpression of Plagl2 (pleiomorphic adenoma gene-like 2), a zinc finger transcription factor, and knockdown of Dyrk1a (dual specificity tyrosine phosphorylation-regulated kinase 1a), a Down syndrome-related kinase, most efficiently activated neurogenesis in the hippocampal dentate gyrus of both 6- and 19-mo-old mice, and we named this combination $\mathrm{iPaD}$ (inducing Plagl2 and anti-Dyrk1a activity).

We first examined the short-term effects of lentivirus with $\mathrm{iPaD}$ under the control of the Hes5 promoter $(\mathrm{iPaD}$ lentivirus) on aged NSCs. Two weeks after the control or $\mathrm{iPaD}$ virus infection at 18 mo of age, very few were activated by the control virus, whereas more than half of the $\mathrm{iPaD}$ virus-infected cells were activated $\left(\mathrm{MCM}^{+}\right.$and/or $\mathrm{BrdU}^{+}$) (Fig. 1E,F), which included $\mathrm{Sox}^{+}$; $\mathrm{GFAP}^{+}$active NSCs (Fig. 1G, arrowhead) and $\mathrm{DCX}^{+}$; dendrite ${ }^{+}$immature neurons (Fig. $1 \mathrm{H}$, arrowheads). Many of the $\mathrm{iPaD}$ virus-infected $\mathrm{MCM}^{-} \mathrm{BrdU}^{-}$(nonactivated) cells were astrocytes, which did not become active or proliferative by $\mathrm{iPaD}$. When the $\mathrm{iPaD}$ lentivirus was injected into nonneurogenic brain regions, many astrocytes were labeled because the Hes 5 promoter is active in astrocytes. However, none of the virus-infected cells expressed MCM2 or DCX (Supplemental Fig. S3D). We also examined the effects of $\mathrm{iPaD}$ in the LV-SVZ and found that NSCs in this region were activated similarly to those in the DG-SGZ (Supplemental Fig. S3A-C). These results suggest that $\mathrm{iPaD}$ can specifically activate NSCs.

\section{Long-term effect of iPaD on neurogenesis}

To examine the long-term effect of the $\mathrm{iPaD}$ lentivirus on neurogenesis in the aged brain, we introduced it into the hippocampal dentate gyrus of 18 -mo-old mice. At this age, there were only a few proliferative cells $\left(\mathrm{MCM}^{+}\right)$, including activated NSCs and IPCs, and immature neurons $\left(\mathrm{DCX}^{+}\right.$; dendrite $\left.{ }^{+}\right)$in this region, and the control lentivirus did not affect their numbers (Fig. 2A,B [panel B1],C,D). In contrast, the iPaD lentivirus infection activated NSCs efficiently and induced the formation of immature neurons
1 mo after infection (19 mo of age) (Fig. 2A,B [panel B2],C, D). A similar effect was observed even 8 and $12 \mathrm{wk}$ after infection (20 and 21 mo of age, respectively) (Fig. 2B [panels $\mathrm{B} 3, \mathrm{~B} 4], \mathrm{C}, \mathrm{D})$, suggesting that neurogenesis is activated continuously by the $\mathrm{PaD}$ lentivirus in the aged brain. Plagl2 alone also activated neurogenesis, but less efficiently than the $\mathrm{iPaD}$ lentivirus (Fig. 2A,C,D). These results suggested that NSCs activated by the $\mathrm{iPaD}$ lentivirus proliferate continuously and are not exhausted even after $3 \mathrm{mo}$. In wild-type hippocampi, the number of $\mathrm{MCM}^{+}$or $\mathrm{DCX}^{+}$cells was significantly decreased during aging and mostly disappeared at $18 \mathrm{mo}$ of age (Fig. 2E). However, the $\mathrm{iPaD}$ lentivirus increased the number of these cells in the hippocampal dentate gyrus of the aged brain (19 mo of age) to a level comparable with 9-mo-old or even younger wild-type mice (Fig. 2E), suggesting that neurogenesis in the aged brain can be reactivated effectively by the $\mathrm{iPaD}$ lentivirus.

\section{Improved cognitive function by $\mathrm{iPaD}$}

To examine whether activated neurogenesis improves the cognitive function of aged mice, we analyzed spatial learning and memory with the Barnes maze test. Using this test, it was shown previously that spatial learning and memory are dependent on neurogenesis in the hippocampal dentate gyrus (Imayoshi et al. 2008), and that aged mice exhibit poorer performance than young mice, requiring a longer distance and latency to reach the target hole in the training session (Shoji and Miyakawa 2019). We used two groups of 19-mo-old mice-one injected with the control lentivirus and the other injected with the $\mathrm{iPaD}$ lentivirus 1 mo before the test (Fig. 2F). We found that those injected with the $\mathrm{iaD}$ lentivirus reached the target hole via shorter distances, made fewer errors, and had shorter latencies than those injected with the control lentivirus (Fig. 2G-I; Supplemental Fig. S4A-C). In the first probe test ( $1 \mathrm{~d}$ after training), $\mathrm{iPaD}$ mice stayed longer at the target hole than control mice (Fig. 2J; Supplemental Fig. S4D). Furthermore, in the second probe test ( $7 \mathrm{~d}$ after retraining), $\mathrm{iPaD}$ mice still stayed longer around the target region than the other regions, whereas control mice did not (Supplemental Fig. S4E,F). These data indicated that injection of the $\mathrm{iPaD}$ lentivirus improves the performance of aged mice in the Barnes maze test.

We next tested novel object recognition memory, which is dependent on hippocampal activity (Clark et al. 2000). Mice from both groups were individually exposed to two copies of an identical object in the testing box for 10 min and then returned $24 \mathrm{~h}$ later to the same box containing one new but identical copy of the original object alongside one novel object (Supplemental Fig. S4G). iPaD mice visited the novel object more often and spent a longer time investigating it than control mice (Supplemental Fig. S4H, I), suggesting that recognition memory is improved by injection of the $\mathrm{iPaD}$ lentivirus. Taken together, these data indicated that injection of the $\mathrm{iPaD}$ lentivirus activates neurogenesis in the aged brain and improves learning and memory ability. 
A

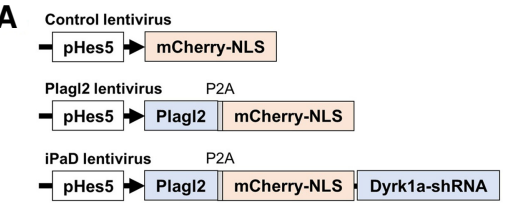

B
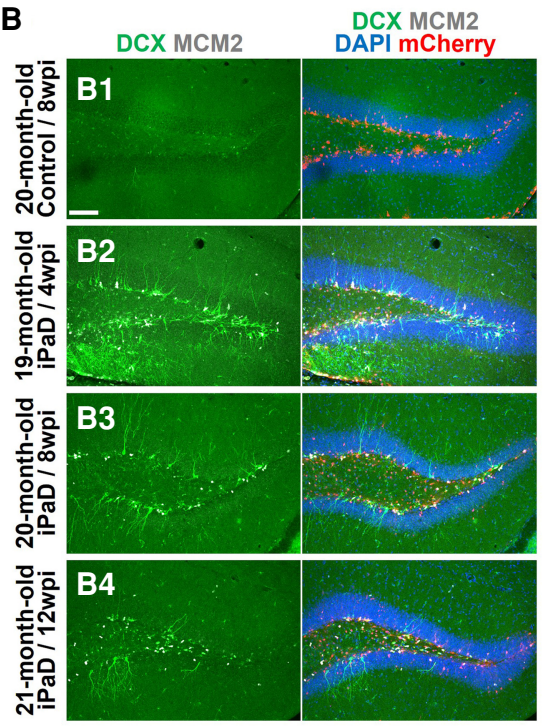

F $\quad$ Barnes maze test
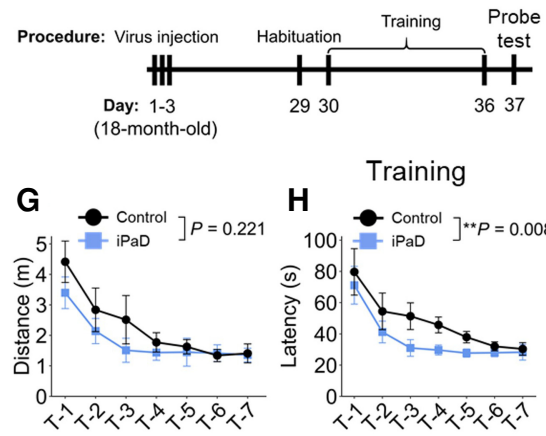

Day

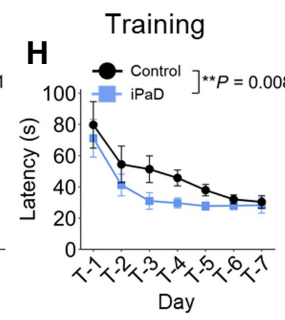

Day
C
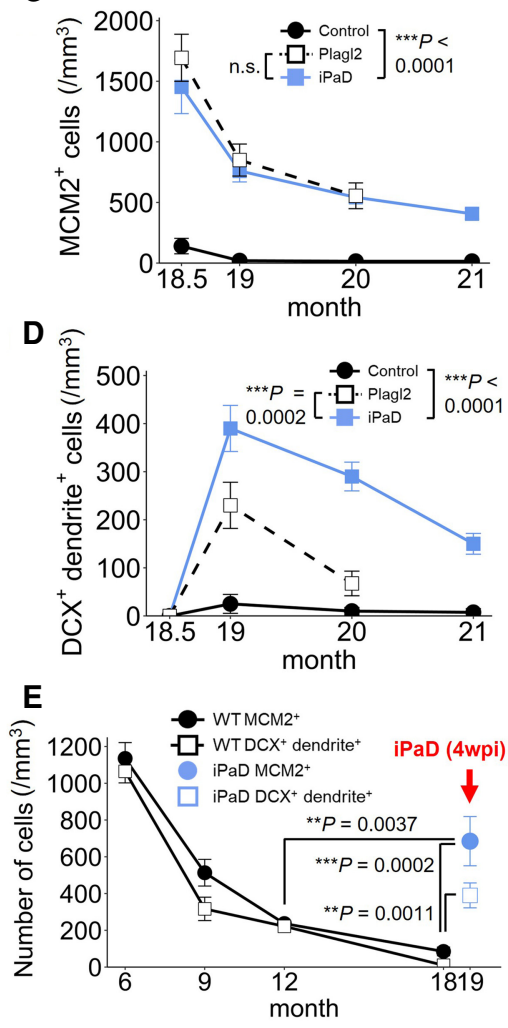

J Probe test

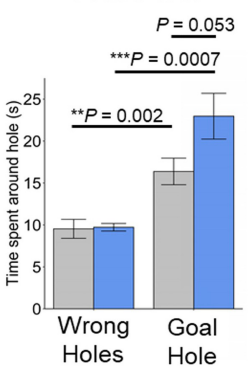

Figure 2. Long-term effect of the iPaD lentivirus on neurogenesis. $(A)$ Schematic structures of the control, Plagl2, and $\mathrm{iPaD}$ lentiviruses. (B) The control (panel B1) or iPaD (panels B2$B 4)$ lentivirus was injected into the hippocampal dentate gyrus of 18-mo-old mice. Immunohistochemical analysis was performed at $8 \mathrm{wpi}$ of the control lentivirus (20 mo of age; panel B1) and at 4wpi (19 mo of age; panel B2), 8 wpi (20 mo of age; panel B3), or 12wpi (21 mo of age; panel $B 4)$ of iPaD lentivirus. $(C, D)$ Quantification of active NSCs/IPCs $\left(\mathrm{MCM}^{+}\right.$; C) and immature neurons $\left(\mathrm{DCX}^{+}{ }^{+}\right.$dendrite $^{+}$; $D$ ) in the hippocampal dentate gyrus after virus injection at 18 mo of age. Two-way ANOVA with Bonferroni's post hoc test. Non-virus-infected cells were included for quantification, but virtually all $\mathrm{MCM}^{+}$or $\mathrm{DCX}^{+}$dendrite ${ }^{+}$ cells at 20 and $21 \mathrm{mo}$ of age were mCherry ${ }^{+}$. (E) Quantification of $\mathrm{MCM}^{+}$active NSCs/ IPCs and $\mathrm{DCX}^{+}$dendrite ${ }^{+}$immature neurons in the wild-type hippocampal dentate gyrus at $6,9,12$, and $18 \mathrm{mo}$ of age. Quantification at 4 wpi of $\mathrm{iPaD}$ lentivirus injection into 18mo-old mice (19 mo of age) is shown at the right. At least four samples were examined for each condition. One-way ANOVA with Tukey HSD post hoc test was conducted. Each value represents the mean \pm SEM. Scale bar, $50 \mu \mathrm{m}$. $(F)$ Schedule of Barnes maze test. Control or $\mathrm{iPaD}$ lentivirus was injected into the hippocampal dentate gyrus of 18-mo-old male mice. $N=10$ for control, $N=10$ for $\mathrm{iPaD}$ male mice. $(G-I)$ Quantification of the walking distance $(G)$, latency $(H)$, and errors $(I)$ before entering the target hole. Error bars indicate SEM. Two-way mixed ANOVA. (J) Time spent around the target hole was measured at the probe test. Error bars indicate SEM. (**) $P<$ $0.01,\left(^{* * *}\right) P<0.001$, one-way ANOVA with Tukey's HSD test.

\section{Clonal analysis of NSCs with iPaD}

The above results indicated that $\mathrm{iPaD}$ can activate functional neurogenesis in the aged brain. We next examined to what extent the proliferative and neurogenic potential of NSCs can be rejuvenated by $\mathrm{iPaD}$. To this end, we performed a sparse labeling approach using a lentivirus expressing the tamoxifen-inducible Cre recombinase $\mathrm{CreER}^{\mathrm{T} 2}$ together with Plagl2 and anti-Dyrkal activity under the control of the Hes5 promoter (iPaD-CreER ${ }^{\mathrm{T} 2}$ lentivirus) (Fig. 3A). As a control, we used a lentivirus expressing CreER ${ }^{\mathrm{T} 2}$ only under the control of the Hes 5 promoter (control-CreER ${ }^{\mathrm{T} 2}$ lentivirus) (Fig. 3A). These viruses were introduced into the hippocampal dentate gyrus of 8and 18-mo-old Ai14 mice, in which Cre recombinase labels infected not only NSCs (Fig. 3B) but also their progeny with tdTomato (Madisen et al. 2010). At day 5 after virus infection, a low dosage of tamoxifen was administered for $3 \mathrm{~d}$ for sparse labeling of NSCs, and brain sections

were examined 3 wk later (Fig. 3A). To determine the virus-infected cell types, we first examined control-CreER ${ }^{\mathrm{T} 2}$ lentivirus-infected brains at $1 \mathrm{wk}$ after tamoxifen treatment. We found that $\sim 40 \%$ of tdTomato $^{+}$cells exhibited radial glia-like (RGL) morphology and expressed GFAP and Sox2, indicating that they were quiescent NSCs (Supplemental Fig. S5A, A", B). The other tdTomato ${ }^{+}$cells were mostly isolated single astrocytes (Supplemental Fig. S5A, $\left.\mathrm{A}^{\prime}, \mathrm{C}\right)$. Similarly, $3 \mathrm{wk}$ after tamoxifen treatment, 30\%$50 \%$ of the tdTomato ${ }^{+}$clones contained RGL cells (Fig. $3 \mathrm{~B})$, while the others were isolated single astrocytes. As the Hes5 promoter is also active in astrocytes, it is likely that those isolated single tdTomato ${ }^{+}$astrocytes were infected directly with the virus rather than differentiating from virus-infected NSCs. Therefore, tdTomato $^{+}$single astrocytes were excluded from the clonal analysis.

To determine the composition of each clone derived from single NSCs, we examined virus-infected brains 3 wk after the last day of tamoxifen treatment (Fig. 3A), 

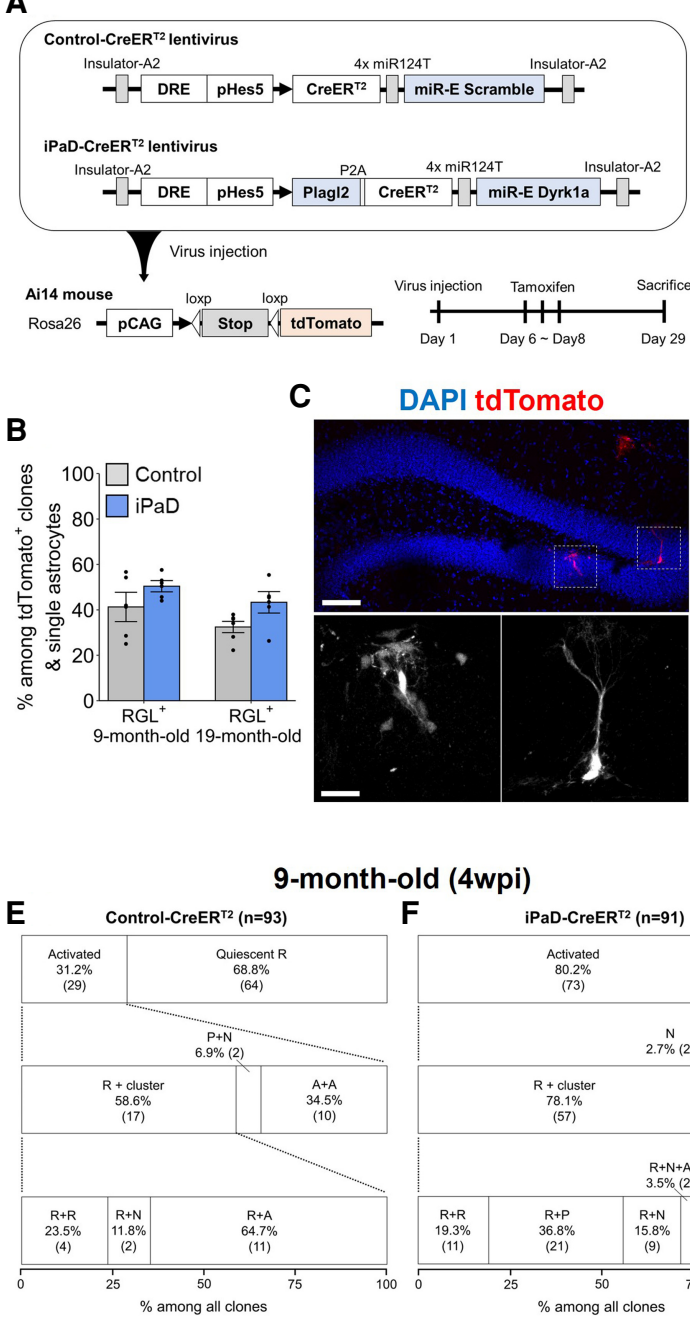

-old (4wpi)



D
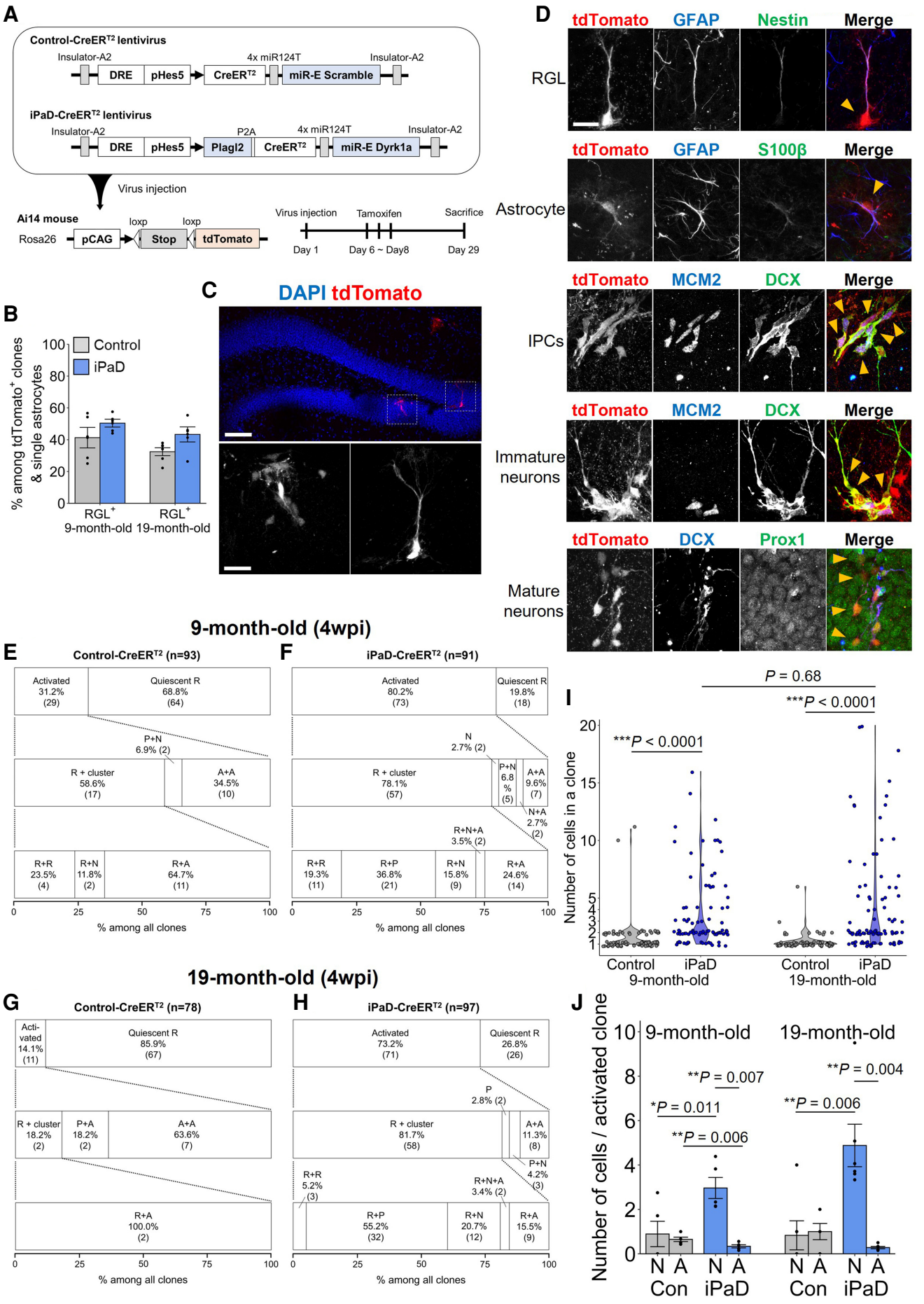

Figure 3. Clonal analysis of iPaD lentivirus-infected NSCs. (A) Strategy for clonal analysis using Ail4 mice. Schematic structures of the control-CreER ${ }^{\mathrm{T} 2}$ and $\mathrm{iPaD}-\mathrm{CreER}^{\mathrm{T} 2}$ lentiviruses and the Rosa26 locus of Ail4 mice (bottom left), and the schedule of experiments for sparse labeling of NSCs (bottom right). (B) Quantification of clones containing RGL cells. (C) Immunohistological and morphological analyses of sparsely labeled cells (tdTomato $\left.{ }^{+}\right) .(D)$ Immunohistological and morphological analyses of sparsely labeled cells $\left(\right.$ tdTomato $\left.^{+}\right)$ from control-CreER ${ }^{\mathrm{T} 2}$ (top two panels) and iPaD-CreER ${ }^{\mathrm{T} 2}$ (bottom three panels) lentivirus-infected hippocampal dentate gyrus. Cell types were determined by morphology and the following markers (indicated by yellow arrowheads): RGL cells $\left(\mathrm{GFAP}^{+} \mathrm{Nestin}^{+}\right.$), astrocytes $\left(\mathrm{GFAP}^{+} \mathrm{S} 100 \beta^{+}\right)$, IPCs $\left(\mathrm{MCM}^{+} \mathrm{DCX}^{+}\right.$dendrite $\left.{ }^{-}\right)$, immature neurons $\left(\mathrm{MCM}^{-} \mathrm{DCX}^{+}\right.$dendrite $\left.{ }^{+}\right)$, and mature neurons $\left(\mathrm{DCX}^{-} \mathrm{Proxl}^{+}\right)$. $(E-H)$ Quantification of the clonal composition of sparsely labeled NSCs with the control-CreER ${ }^{\mathrm{T} 2}(E, G)$ and iPaD-CreER ${ }^{\mathrm{T} 2}(F, H)$ lentiviruses in 9-mo-old $(E, F)$ and 19-mo-old $(G, H)$ Ail4 mice. The number in parentheses indicates the number of each clone. (R) RGL cell, (P) IPC, (N) immature and mature neuron, (A) astrocyte. The number of clones per hemisphere was $38.3 \pm 2.7$ at 9 mo of age and $43.5 \pm 3.6$ at 19 mo of age. (I) Clonal sizes of sparsely labeled NSCs at 9 mo of age (left) and 19 mo of age (right). One-way ANOVA with Tukey HSD post hoc test was conducted. $(J)$ Quantification of $\mathrm{DCX}^{+}$IPCs/neurons and astrocytes per activated clone. Six samples were examined for each condition. (N) IPCs and immature and mature neurons, (A) astrocytes. Two-way ANOVA with Bonferroni's post hoc test was conducted. Each value represents the mean \pm SEM. Scale bars: $C($ top $), 100 \mu \mathrm{m} C($ bottom) $, D, 20 \mu \mathrm{m}$. 
which exhibited sparse labeling (Fig. 3C; Supplemental Fig. S5A). We used immunohistological and morphological markers to identify RGL cells, IPCs, immature and mature neurons, and astrocytes (Fig. 3D; Supplemental Fig. S5D,E) and characterized a total of 93 and 91 clones from the control-CreER ${ }^{\mathrm{T} 2}$ lentivirus-infected and $\mathrm{iPaD}$ $\mathrm{CreER}^{\mathrm{T} 2}$ lentivirus-infected brains, respectively, at $9 \mathrm{mo}$ of age (at 4 wk postinfection of 8-mo-old brains). In control-CreER ${ }^{\mathrm{T} 2}$ lentivirus-infected brains, $68.8 \%$ (64 out of 93) of the clones consisted of one RGL cell (Fig. 3E,I), while only $31.2 \%$ (29 out of 93 ) of the clones consisted of two or more cells (Fig. 3E), indicating that the majority of the control virus-infected cells remained as quiescent NSCs. In agreement with this notion, the average clonal size was 1.5 cells/clone after 3 -wk tracing. Among the clones derived from activated NSCs $(n=29)$ ), $13.8 \%$ (four out of 29) consisted of two RGL cells $(R+R)$ (Fig. 3E), suggesting that symmetric cell division occurs occasionally at this stage. Among these activated clones $(n=29)$, only $13.8 \%[2(\mathrm{P}+\mathrm{N})+2(\mathrm{R}+\mathrm{N})=4]$ contained $\mathrm{DCX}^{+}$IPCs or neurons, while $\sim 72.4 \%[10(\mathrm{~A}+\mathrm{A})+11(\mathrm{R}+\mathrm{A})=21]$ contained astrocyte(s) (Fig. 3E). These results indicated that wild-type NSCs exhibit low proliferative/neurogenic potential at 9 mo of age (Fig. 3E, J). In contrast, in iPaD$\mathrm{CreER}^{\mathrm{T} 2}$ lentivirus-infected brains, only $19.8 \%$ (18 out of 91) of the clones consisted of one RGL cell (Fig. 3F,I), while $80.2 \%$ (73 out of 91) of the clones contained two or more cells (Fig. 3F), indicating that the majority of the virus-infected NSCs were activated. In agreement with this notion, the average clonal size was 3.6 cells/clone after 3-wk tracing. Among the clones derived from activated NSCs $(n=73), 56.2 \%[2 \mathrm{~N}+5(\mathrm{P}+\mathrm{N})+2(\mathrm{~N}+\mathrm{A})+21(\mathrm{R}+\mathrm{P})+$ $9(\mathrm{R}+\mathrm{N})+2(\mathrm{R}+\mathrm{N}+\mathrm{A})=41]$ contained $\mathrm{DCX}^{+}$IPCs or neurons, while $34.2 \% \quad[2(\mathrm{~N}+\mathrm{A})+7(\mathrm{~A}+\mathrm{A})+2(\mathrm{R}+\mathrm{N}+\mathrm{A})+$ $14(\mathrm{R}+\mathrm{A})=25]$ were astrogenic (Fig. $3 \mathrm{~F})$. These results indicated that the $\mathrm{iPaD}$ lentivirus substantially enhances the proliferative ( 2.4-fold increase) and neurogenic ( 4.1-fold increase) potential of NSCs at 9 mo of age (Fig. 3I,J).

We next characterized a total of 78 and 97 clones from control-CreER $^{\mathrm{T} 2}$ lentivirus-infected and $\mathrm{iPaD}^{-C r e E R}{ }^{\mathrm{T} 2}$ lentivirus-infected brains, respectively, at 19 mo of age (at 4 wk postinfection of 18 -mo-old brains). In control$\mathrm{CreER}^{\mathrm{T} 2}$ lentivirus-infected brains, $85.9 \%$ (67 out of 78 ) of the clones consisted of one RGL cell (Fig. 3G,I), indicating that the majority of the control virus-infected cells remained as quiescent NSCs. Furthermore, the other clones were mostly astrogenic, and no clones contained neurons, while very few $(2.6 \%$, two out of 78$)$ contained IPCs (Fig. $3 \mathrm{G})$. The average clonal size was 1.2 cells/clone after 3 -wk tracing, which is similar to that at 9 mo of age. These results indicated that NSCs exhibit very low proliferative and virtually no neurogenic potential at 19 mo of age (Fig. 3I,J). In contrast, in $\mathrm{iPaD}-\mathrm{CreER}^{\mathrm{T} 2}$ lentivirus-infected brains, only $26.8 \%$ (26 out of 97) of the clones consisted of one RGL cell, while $73.2 \%$ (71 out of 97) of the clones consisted of two or more cells (Fig. $3 \mathrm{H}$ ), indicating that many virus-infected NSCs were activated. Among the clones derived from activated NSCs $(n=71), 71.8 \%[2 \mathrm{P}+3(\mathrm{P}+\mathrm{N})+$ $32(\mathrm{R}+\mathrm{P})+12(\mathrm{R}+\mathrm{N})+2(\mathrm{R}+\mathrm{N}+\mathrm{A})=51]$ contained $\mathrm{DCX}^{+}$ IPCs or neurons, while $26.8 \%[8(\mathrm{~A}+\mathrm{A})+2(\mathrm{R}+\mathrm{N}+\mathrm{A})+9$
$(\mathrm{R}+\mathrm{A})=19$ ] were astrogenic (Fig. $3 \mathrm{H})$. The average clonal size was 4.1 cells/clone for 3 -wk tracing. These results indicated that the $\mathrm{iPaD}$ lentivirus endows nonproliferative, nonneurogenic NSCs with proliferative and neurogenic potential at 19 mo of age (Fig. 3I,J). The clonal size of $\mathrm{iPaD}$ lentivirus-infected 19-mo-old NSCs was even larger than 4.1 cells/clone, if only activated NSCs are considered ( 4.9 neurons/clone in 3-wk tracing) (Fig. 3J), and this value was comparable with or larger than that of wild-type activated $\left(\mathrm{Ascll}^{+}\right)$NSCs at 2 mo of age, which generated, on average, 4.8 neurons in 2-mo tracing (Pilz et al. 2018). These results suggest that $\mathrm{iPaD}$ can rejuvenate $19-\mathrm{mo}-$ old NSCs to function like 2-mo-old or even younger NSCs.

\section{Gene expression analysis of iPaD-dependent rejuvenation of aged NSCs}

To characterize the rejuvenation ability of $\mathrm{iPaD}$, we analyzed the senescence-associated factors $\beta$-galactosidase, p16 ${ }^{\text {Ink4a }}$, and p19 ${ }^{\text {Arf }}$ (Molofsky et al. 2006; Nishino et al. 2008). Their expression was up-regulated in aged NSCs compared with young NSCs but repressed by $\mathrm{iPaD}$, indicating that $\mathrm{iPaD}$ can reverse the aging process of NSCs (Fig. 4A-D). It was previously shown that Plagl2 enhances the self-renewal of telencephalic neural progenitors and glioblastoma cells (Zheng et al. 2010; Adnani et al. 2018), while a proper dosage of Dyrk1a, a gene associated with Down syndrome, which accelerates aging (Franceschi et al. 2019), is important for normal neurogenesis (Fotaki et al. 2002), but the mechanism by which iPaD rejuvenates aged NSCs is unclear. To investigate the mechanism, we next performed RNA-seq analysis of E13.5, young (1-moold), adult (9-mo-old), and aged (19-22-mo-old) NSCs infected with the control or $\mathrm{PaD}$ virus (Fig. 4E; Supplemental Table S3). Because of the technical difficulty in obtaining NSCs from DG-SGZ in the aged mice, we used NSCs from LV-SVZ. We confirmed that Plag12 expression is down-regulated in aged NSCs but up-regulated by $\mathrm{iPaD}$, while Dyrk $1 a$ expression is up-regulated in aged NSCs but down-regulated by iPaD (Supplemental Fig. S6A). Principal component (PC) analysis showed a high reproducibility between biological duplicates or triplicates of each sample and dynamic transcriptomic changes caused by aging (Fig. $4 F$ ), which exhibited a high similarity to the previously published data (Supplemental Fig. S6B; Kalamakis et al. 2019). Interestingly, the transcriptomic profiles of aged NSCs became very similar to those of 1-mo-old NSCs after infection with the $\mathrm{iPaD}$ virus, agreeing with the above observation that $\mathrm{iPaD}$ can rejuvenate the proliferative and neurogenic potential of aged NSCs in the DG-SGZ (Fig. 4F; Supplemental Fig. S6C). The gene ontology (GO) terms of PC3, which represent iPaD-induced rejuvenation, included genes involved in development, cell fate commitment, and response to interferon- $\beta$ (Supplemental Fig. S6D,E). Analysis by $c$-means clustering revealed eight patterns of transcriptomic changes in NSCs from embryonic to aged stages (Fig. 4G; Supplemental Fig. S6F). GO enrichment analysis indicated that genes involved in cell proliferation, such as Ccnd, Cdk4, and E2f1, are enriched in 
Kaise et al.
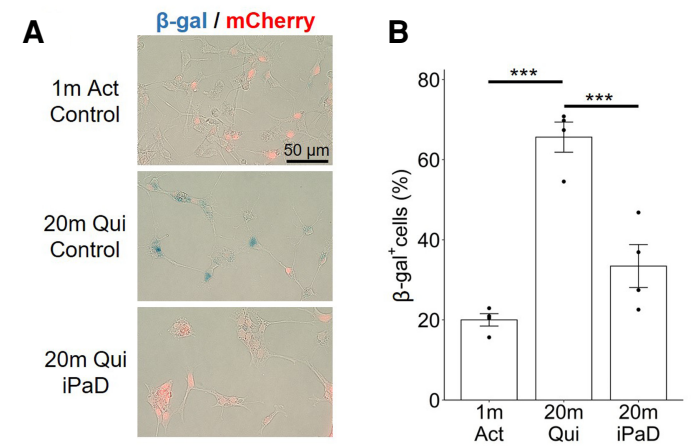

$$
\text { C }
$$
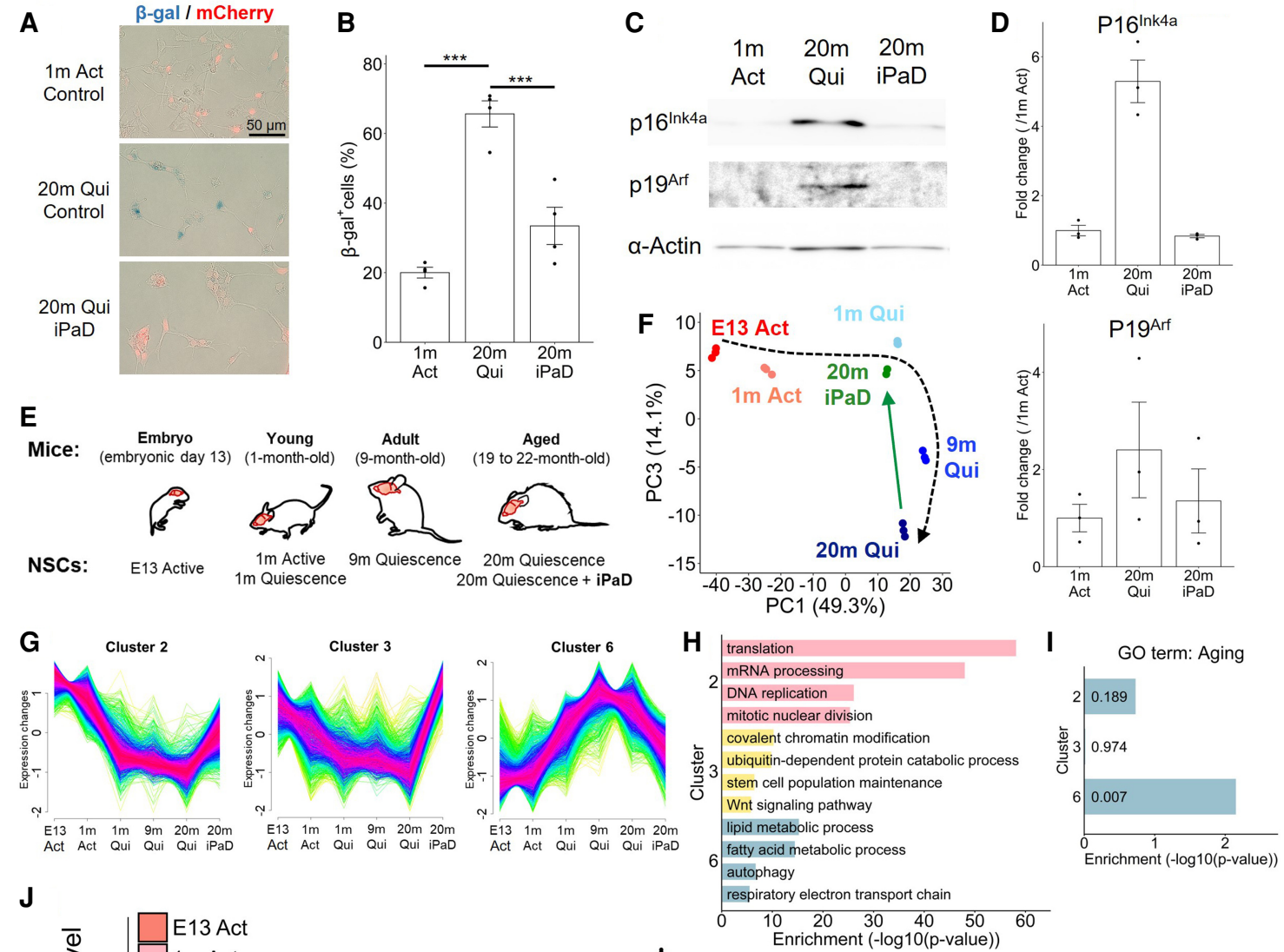

$\mathbf{J}$

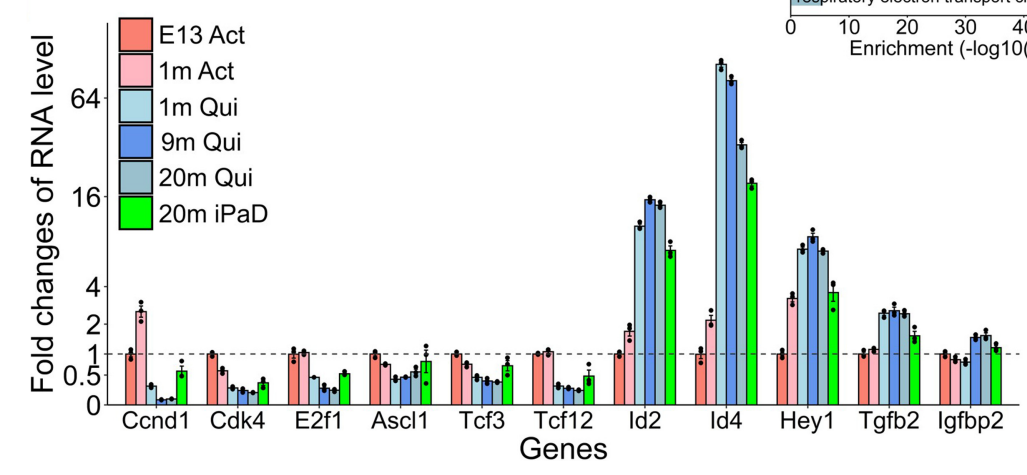

Figure 4. The mechanism of iPaD-dependent rejuvenation of aged NSCs. $(A-D) \beta$-Galactosidase staining $(A)$, quantification of its positive cells $(B)$ and $\mathrm{p} 16^{\mathrm{INK} 4 \mathrm{a}}$ and $\mathrm{p} 19^{\mathrm{Arf}}$ expression $(C)$, and quantification $(D)$ in 1-mo-old NSCs infected with the control virus and 20-mo-old NSCs infected with the control or $\mathrm{iPaD}$ virus. Intensities of $\mathrm{p} 16^{\text {Ink4a }}$ and $\mathrm{p} 19^{\mathrm{ARF}}$ bands were normalized with the intensity of $\alpha-\mathrm{Actin}$. $(E)$ E13.5, young (1-mo-old), adult (9-mo-old), and aged (19- to 22-mo-old) NSCs were infected with the control virus. Aged NSCs were also infected with $\mathrm{iPaD}$ virus. $(F)$ Principal component analysis (PCA) of the transcriptomes shown in $E$. $(G-I)$ Analysis by $c$-means clustering revealed eight clusters of transcriptomic changes in NSCs from embryonic to aged stages. Transcriptomic changes $(G)$, gene ontology analyses $(H)$, and enrichment of aged genes $(I)$ of clusters 2,3 , and 6 are shown. $(J)$ Fold changes of RNA levels of representative genes in clusters 2,3 , and 6.

clusters 2 and 3 (Fig. 4H,J; Supplemental Fig. S6G), whose expression is down-regulated in aged NSCs compared with embryonic NSCs but up-regulated by iPaD (Fig. 4G). In contrast, genes involved in aging such as Tgfb2 and Igfbp2 are enriched in cluster 6 (Fig. 4I,J; Supplemental Fig. S6H), whose expression is up-regulated in aged NSCs but repressed by $\mathrm{iPaD}$ (Fig. 4G). These results suggest that $\mathrm{iPaD}$ can rejuvenate aged NSCs by up-regulating embryonic-high genes and repressing aged-high genes.
Further gene expression analyses showed that $\mathrm{iPaD}$ down-regulated quiescence-related genes such as Id4 (Blomfield et al. 2019; Zhang et al. 2019) and up-regulated activation-related genes such as Ascl1 (Fig. 4J; Supplemental Fig. S6I,J; Andersen et al. 2014; Sueda et al. 2019). Ascl1 expression is mostly negative in the aged brain (Fig. 5A), but subsets of iPaD lentivirus-infected cells expressed Ascll protein after 4 wk of infection in 19-mo-old hippocampal dentate gyrus, whereas none of 
the control lentivirus-infected cells expressed Ascll (Fig. 5B). Furthermore, Ascll expression in cultured quiescent NSCs was up-regulated by $\mathrm{iPaD}$ but not by the control (Supplemental Fig. S7), indicating that iPaD can induce Ascl1 protein expression in quiescent NSCs. We next examined whether iPaD lentivirus-infected cells express Ascl1 in an oscillatory manner, a hallmark feature of activated NSCs (Imayoshi et al. 2013; Sueda et al. 2019). The $\mathrm{iPaD}$ lentivirus was injected into the dentate gyrus of 10mo-old Ascll reporter mice, and 4 wk after injection (11 mo of age), time-lapse imaging of brain slices was performed. Ascll expression induced by the $\mathrm{iPaD}$ lentivirus was oscillatory (Fig. $5 \mathrm{C}$ ), suggesting that $\mathrm{iPaD}$ is able to maintain active NSCs in the aged brain by inducing dynamic Ascll expression for an extended period of time.

\section{Epigenetic analysis of iPaD-dependent rejuvenation of aged NSCs}

Because Plagl2 is a zinc finger transcription factor, we next performed Plagl2 chromatin immunoprecipitation assays with sequencing (ChIP-seq) of HA-tagged Plagl2overexpressing NSCs to identify its downstream targets.
Motif enrichment analysis revealed the consensus sequence GGGGCCC recognized by Plag12, which matched the previously characterized Plagll/Zacl-binding sites (Fig. 6A; Hensen et al. 2002; Varrault et al. 2017), and these Plag12-binding regions were identified in the promoter of 4731 genes (Supplemental Table S4). GO terms involved in gene regulation and chromatin modifications were enriched in genes containing Plagl2-binding sites and up-regulated by $\mathrm{iPaD}$ (Fig. 6B). Expression of chromatinmodifying enzymes and DNA methylation enzymes decreased with aging but were recovered by $\mathrm{iPaD}$ (Fig. 6C, D). More than $70 \%$ of chromatin-modifying enzymes belong to clusters 2 and 3 , and many of them contain Plag12-binding regions around their promoters (Supplemental Fig. S8). These results suggest that $\mathrm{PaD}$ regulates rejuvenation by changing the chromatin accessibility.

To examine this possibility, we performed an assay for transposase-accessible chromatin by sequencing (ATACseq) to identify the age-associated changes in global chromatin accessibility and examined whether aged profiles can be reversed by $\mathrm{iPaD}$. It was previously reported that chromatin accessibility profiles were distinct between embryonic and adult NSCs (Berg et al. 2019), raising the
A
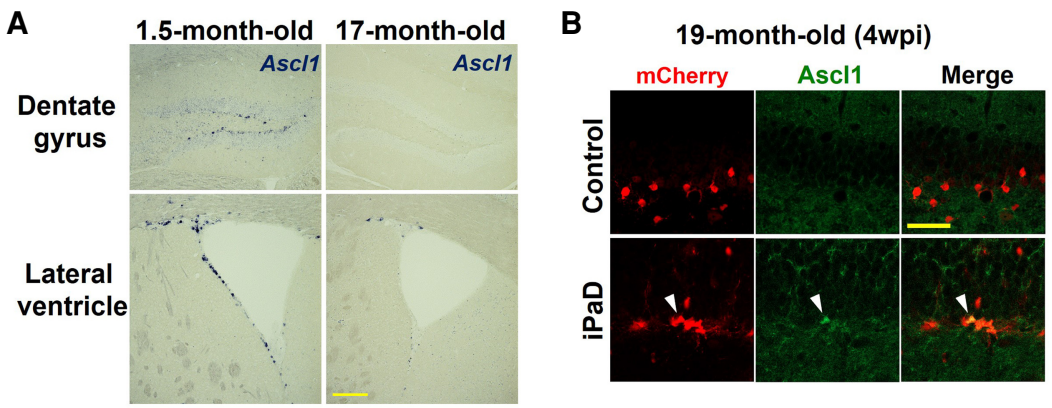

C 11-month-old (4wpi) Luc2-Ascl1


cell1
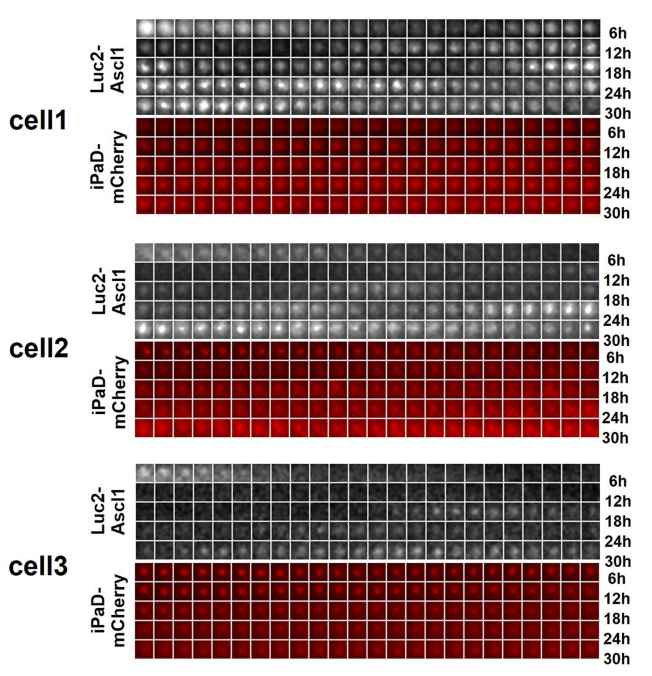

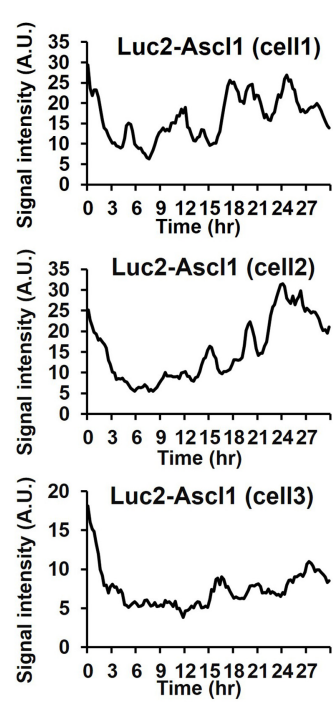

Figure 5. Induction of Ascll expression by the $\mathrm{iPaD}$ lentivirus. (A) In situ hybridization of Ascl1 in the hippocampal DG-SGZ and the LVSVZ of 1.5- and 17-mo-old mice. $(B)$ The $\mathrm{iPaD}$ or control lentivirus was injected into the hippocampal dentate gyrus of 18-mo-old mice, and 4 wk later, the infected regions were examined immunohistochemically. Subsets of $\mathrm{PaD}$ lentivirus-infected cells expressed Ascll (arrowhead), whereas none of the control lentivirus-infected cells did. $(C)$ Bioluminescence imaging and quantification of Luc2-Ascll levels in $\mathrm{iPaD}$ lentivirusinfected cells. The $\mathrm{iPaD}$ lentivirus was injected into the hippocampal dentate gyrus of 10-mo-old Ascl1 reporter mice, in which Luc2-Ascll fusion protein was expressed from the endogenous Ascl1 locus. At 4 wk after injection (11 mo of age), time-lapse imaging of brain slices was performed. Luc2-Ascl1 expression occurred in $\mathrm{iPaD}$ virus-infected cells (arrowheads). Three representative cells were quantified. Scale bars: $A, 200 \mu \mathrm{m}$; $B, 30 \mu \mathrm{m} ; C, 100 \mu \mathrm{m}$. 
Kaise et al.

A

\begin{tabular}{|c|c|c|}
\hline \multicolumn{3}{|c|}{ Plagl2 ChIP-seq } \\
\hline & De novo motif & Match \\
\hline 1 & $\begin{array}{c}\text { AAGGGCCCC. } \\
\text { p=1e-1045 }\end{array}$ & $\begin{array}{l}\text { Plagl1 } \\
\text { ZNF692 }\end{array}$ \\
\hline 2 &  & $\begin{array}{l}\text { Sox21 } \\
\text { Sox4 }\end{array}$ \\
\hline 3 & 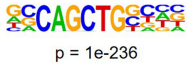 & $\begin{array}{c}\text { Tcf12 } \\
\text { BHLHE22 }\end{array}$ \\
\hline
\end{tabular}

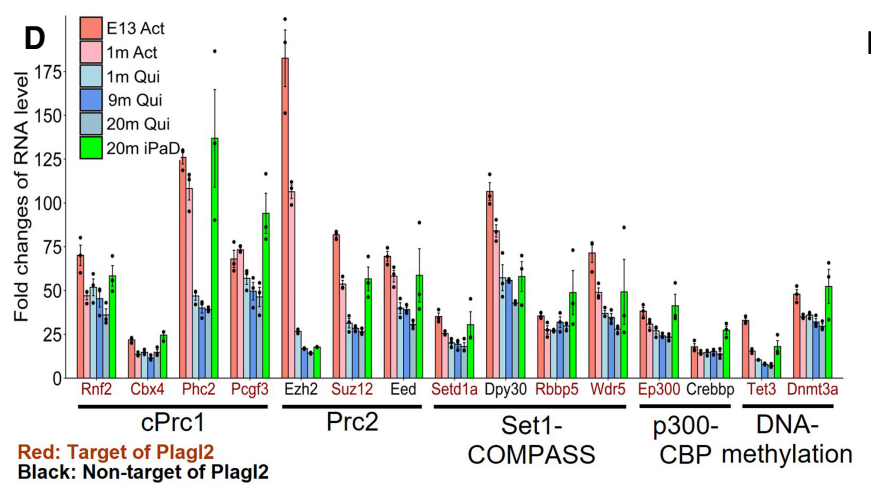

B

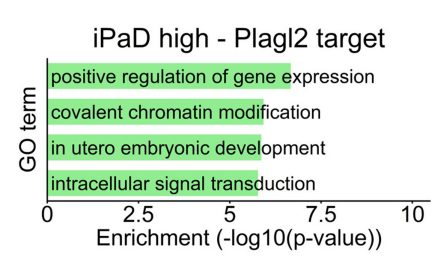

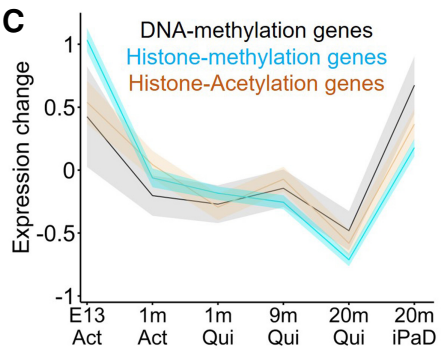

E ATAC-seq

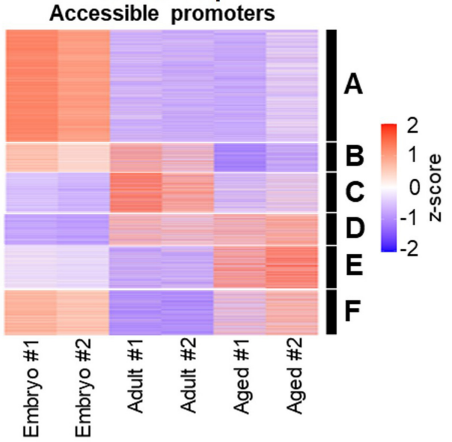

$\mathrm{F}$ Plagl2(+):Ascl1(-) $\quad$ Plagl2(+):Ascl1(+)
Plagl2(-):Ascl1(+)
Plagl2(-):Ascl1(-)

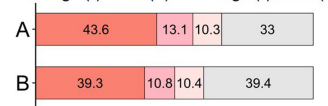

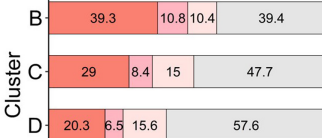

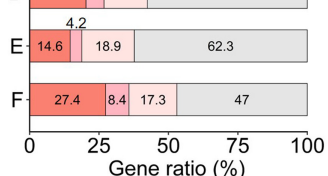

G
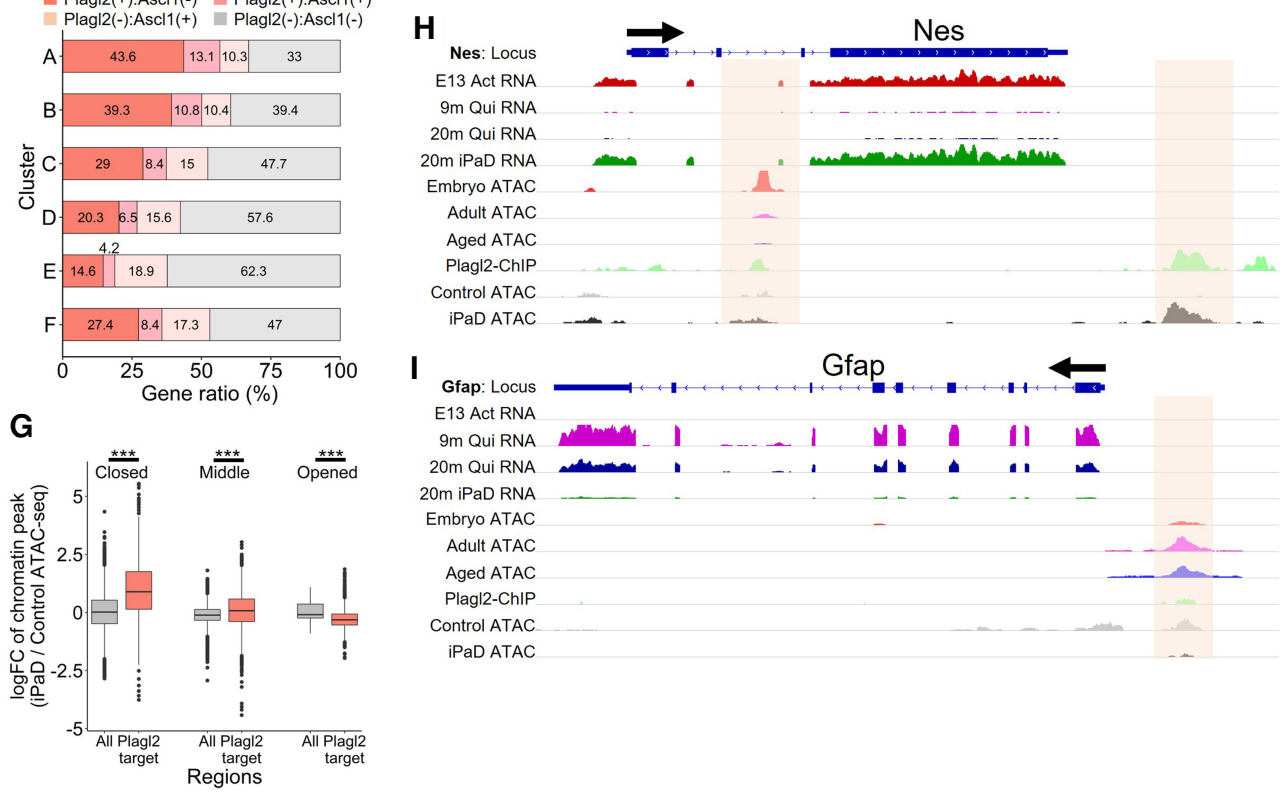

Figure 6. The epigenetic mechanism of iPaD-dependent rejuvenation of aged NSCs. $(A)$ Motif enrichment analysis of Plagl2 ChIP-seq. $|B|$ $\mathrm{GO}$ analysis of genes up-regulated by $\mathrm{iPaD}$ and containing Plagl2-binding sites. $(C, D)$ Changes of chromatin/DNA modification gene expression. (E) Analysis by k-means clustering of ATAC-seq signals around promoters of embryonic, adult, and aged NSCs revealed six clusters. $(F)$ Proportions of Plagl2 and Ascl1 target genes in each cluster. $(G)$ Changes of chromatin accessibility in aged NSCs by iPaD. In aged NSCs, closed genes containing Plagl2-binding sites exhibited higher accessibility by iPaD, while opened genes containing Plagl2-binding sites exhibited lower accessibility by iPaD. $(H, I)$ RNA-seq, ATAC-seq, and Plagl2 ChIP-seq enrichment profiles of Nestin $(H)$ and $G f a p(I)$.

possibility that they could be further changed during aging. ATAC-seq analysis of embryonic (E14.5), adult (6mo-old), and aged (19-20-mo-old) NSCs showed highly correlated signals between biological duplicates in embryonic, adult, and aged NSCs $(r=1.00$ in embryonic, $r=0.97$ in adult, and $r=0.99$ in aged NSCs, Pearson correlation coefficient) (Supplemental Fig. S9A). PCA also showed a high reproducibility between biological duplicates of each sample and revealed that chromatin accessibility profiles were significantly different between adult and aged NSCs, suggesting that the chromatin landscapes dynamically change during aging (Supplemental Fig. S9B). Analysis by $k$-means clustering revealed six patterns of chromatin landscape changes in NSCs from embryonic 
to aged stages (Fig. 6E). Notably, $67.9 \%$ and $11.3 \%$ of the embryonic-high genes belonged to clusters $\mathrm{A}$ and $\mathrm{B}$, respectively, whose chromatin structures are open in embryonic NSCs but mostly inaccessible in aged NSCs, suggesting that a total of $79.2 \%$ of the embryonic-high genes decrease chromatin accessibility during aging (Supplemental Fig. S9C,D). Among these genes, Plagl2- and Ascl1-binding regions are enriched (Fig. 6F,G; Supplemental Fig. S9E), suggesting that Plagl2 and iPaD-inducible Ascll are involved in up-regulation of such embryonichigh genes whose chromatin structures are less accessible in aged NSCs. In agreement with this notion, iPaD preferentially up-regulated Plagl2 target genes compared with nontarget genes irrespective of their chromatin accessibility in aged NSCs (Supplemental Fig. S9F). Furthermore, while $\mathrm{iPaD}$ increased chromatin accessibility $(>1.5$-fold) of 945 genes in aged NSCs, 628 and 168 (84.2\%) of them belonged to clusters $\mathrm{A}$ and $\mathrm{B}$, respectively. These results suggest that $\mathrm{iPaD}$ can reopen many genes whose chromatin structures become less accessible with aging. Indeed, the active NSC-specific gene Nestin exhibited high RNA expression and chromatin accessibility at an embryonic stage and very low RNA expression and chromatin accessibility at an aged stage, but chromatin accessibility of Plagl2 binding regions and RNA expression increased in aged NSCs by iPaD (Fig. 6H). Similarly, in genes involved in proliferation of NSCs, such as E2f1, Tcf3, and Ascl1, RNA expression and chromatin accessibility decreased during aging but increased by iPaD (Supplemental Fig. S9G-I). In contrast, in genes up-regulated during aging, such as Gfap, RNA expression and chromatin accessibility increased during aging but decreased by iPaD (Fig. 6I). These results suggest that $\mathrm{iPaD}$ up-regulates many embryonic-high genes and down-regulates aged-high genes by controlling chromatin accessibility, thereby rejuvenating dormant NSCs.

\section{Discussion}

\section{Rejuvenation of aged NSCs by iPaD}

Aged NSCs are mostly dormant, and even when they are activated, they primarily produce astrocytes. Thus, aged NSCs lose their proliferative and neurogenic potential, leading to the cessation of neurogenesis. In this study, we showed that the $\mathrm{iPaD}$ lentivirus substantially rejuvenated the proliferative and neurogenic potential of NSCs in the aged brain. Clonal analysis by a sparse labeling approach as well as transcriptome analysis indicated that $\mathrm{iPaD}$ can rejuvenate aged NSCs (19-21 mo of age) to a level comparable with those at 1 or 2 mo of age and successfully improved cognition of aged mice. Once rejuvenated and activated by $\mathrm{iPaD}$, aged dormant NSCs can generate, on average, 4.9 neurons but very few astrocytes in 3-wk tracing (Fig. 3J). Furthermore, these activated NSCs were maintained for as long as $3 \mathrm{mo}$ in the aged brain, suggesting that active neurogenesis continues for an extended period of time after $\mathrm{iPaD}$ treatment. Nevertheless, iPaDactivated neurogenesis gradually declined (Fig. 2D). Furthermore, clonal analyses showed that $78.1 \%$ (9-mo-old) and $81.7 \%$ (19-mo-old) of iPaD-activated clones maintained RGL cells 4 wk after activation (Fig. 3F,H), suggesting that $\sim 20 \%$ of activated NSCs are exhausted during this period. However, it is unknown whether this exhaustion is due to limitation of $\mathrm{iPaD}$ or loss of $\mathrm{iPaD}$ activity, and further analyses are requited to answer this question.

A recent study showed that resting NSCs, those once proliferated but returned to quiescence (Urbán et al. 2016), are the major origin of active NSCs in the aged brain (Harris et al. 2021). This population comprises only $3 \%-$ $5 \%$ of the total NSCs, while the other major population is dormant NSCs, which have never proliferated (Harris et al. 2021). Because the $\mathrm{iPaD}$ is able to activate $70 \%-$ $80 \%$ of NSCs in the aged brain, it is likely that it mostly targets dormant NSCs, raising the possibility that the higher the infection efficiency of the $\mathrm{iPaD}$ virus, the more NSCs are activated to produce new neurons.

\section{The mechanism of NSC rejuvenation by $\mathrm{PaD}$}

During aging, the gene expression and accessible chromatin landscapes change dynamically in NSCs. Transcriptome analysis showed that there are eight clusters of genes showing different expression patterns. Among them, clusters 2, 3, and 6 are of particular interest: In clusters 2 and 3, gene expression is down-regulated in aged NSCs compared with embryonic NSCs but up-regulated by $\mathrm{iPaD}$, while in cluster 6 , gene expression is up-regulated in aged NSCs but repressed by $\mathrm{iPaD}$ (Fig. 4G). Genes involved in cell proliferation are enriched in clusters 2 and 3 , while genes involved in aging are enriched in cluster 6 . In addition, chromatin-modifying genes are also enriched in clusters 2 and 3 . These results suggest that $\mathrm{PaD}$ can rejuvenate aged NSCs by up-regulating embryonic-high genes and repressing age-associated genes via modulation of chromatin accessibility. To confirm this possibility, we also examined chromatin accessibility in aged NSCs. ATAC-seq analysis revealed that there are six clusters (A-F) of genes showing different patterns of chromatin landscape changes from embryonic to aged stages. The majority of embryonic-high genes belong to clusters A and $\mathrm{B}$, whose chromatin structures are open in embryonic NSCs but mostly inaccessible in aged NSCs. Interestingly, many genes in clusters A and B contain Plagl2-binding sites as well as $\mathrm{iPaD}$-induced Ascll-binding sites, and therefore it is most likely that their expression is controlled directly or indirectly by $\mathrm{iPaD}$. These results raised the possibility that $\mathrm{iPaD}$ up-regulates gene expression by increasing the chromatin accessibility in aged NSCs. In contrast, some aging-associated genes such as Gfap increased the chromatin accessibility in aged NSCs, but their transcription and chromatin accessibility are repressed by $\mathrm{iPaD}$, suggesting that $\mathrm{iPaD}$ can also down-regulate gene expression by decreasing the chromatin accessibility in aged NSCs. Thus, iPaD can both up-regulate and down-regulate gene expression by modulating the chromatin accessibility, but the detailed mechanism by which iPaD differentially regulates the chromatin structures remains to be analyzed. In addition, while the chromatin/DNA modification gene expression patterns in 
$\mathrm{iPaD}$-treated NSCs are more similar to those of embryonic NSCs (Fig. 6C), their transcriptome is more similar to $1 \mathrm{~m}$ quiescent NSCs (Fig. 4F), suggesting that additional factors, such as environmental conditions, may be required to further rejuvenate aged NSCs.

We also found that $\mathrm{iPaD}$ is able to induce Ascll oscillations, a hallmark feature of active NSCs (Imayoshi et al. 2013; Sueda et al. 2019), in the aged brain. We previously showed that Ascll has dual activities: It induces neuronal differentiation when its expression is continuous, whereas it activates proliferation of NSCs when its expression is oscillatory, indicating that Ascll oscillations are important for the active state of NSCs (Imayoshi et al. 2013; Sueda et al. 2019). In aged NSCs, chromatin structures of Ascl1 are less accessible but become more widely accessible after $\mathrm{iPaD}$ treatment, suggesting that $\mathrm{iPaD}$ is involved in the chromatin accessibility of Ascl1. A single Ascll-expressing cell was found in each $\mathrm{mCherry}^{+}$cluster, which was most likely derived from a single iPaD lentivirus-infected NSC. This observation agrees well with the clonal analysis, which showed that most clusters derived from $\mathrm{iPaD}$ lentivirus-infected NSCs contained a single RGL cell (Fig. 3F,H), suggesting that these activated NSCs repeat an asymmetric cell division, in which one daughter cell remains as an NSC while the other starts neuronal or astrocytic differentiation.

It was previously reported that Plagl2 plays an important role in self-renewal of telencephalic neural progenitors (Adnani et al. 2018). Indeed, we found that Plagl2 alone can increase cell proliferation $\left(\mathrm{MCM}^{+}\right)$as efficiently as iPaD (Fig. 2C), suggesting that Plagl2 endows dormant NSCs with proliferative potential. Plagl2 alone generated fewer $\mathrm{DCX}^{+}$dendrite ${ }^{+}$cells than $\mathrm{iPaD}$ but more than the control (Fig. 2D), suggesting that Plagl2 also has weak neurogenic as well as astrogenic activity. It was also reported that Plagl2 functions as a proto-oncogene by activating Wnt signaling in gliomas (Zheng et al. 2010). However, we observed no tumor formation in the brain 3 mo after $\mathrm{iPaD}$ lentivirus infection, suggesting that $\mathrm{iPaD}$ cannot activate tumorigenesis. Furthermore, whereas the Wnt ligand gene Wnt6 was up-regulated by Plagl2 in p53deficient NSCs (Zheng et al. 2010), it was not much changed in wild-type NSCs by the $\mathrm{iPaD}$ lentivirus. These results suggest that $\mathrm{iPaD}$ is not involved in tumor formation in the brain, and that the downstream events may be different, depending on the cellular context.

$\mathrm{iPaD}$ significantly increased the number of $\mathrm{DCX}^{+}$dendrite $^{+}$cells compared with Plagl2 alone (Fig. 2D), suggesting that inhibiting Dyrk1a endows NSCs with neurogenic potential, although its mechanism remains to be analyzed. Dyrkla is known to prevent nuclear entry of the transcription factors NFATc by phosphorylation and thereby block NFATc activity (Arron et al. 2006), suggesting that $\mathrm{PaD}$ can up-regulate NFATc activity. Interestingly, NFATc4 is included in the embryonic-high genes; however, overexpression of NFATc4 did not efficiently activate quiescent NSCs (Supplemental Table S1). Another NFATc member, NFATc1, is included in the adult-high genes, but knockdown of NFATc1 did not efficiently activate quiescent NSCs (Supplemental Fig. S2C; Supplemen- tal Table S2). Thus, NFATc factors may not be involved in $\mathrm{iPaD}$-induced neurogenesis, and further analyses will be required to identify the target proteins for Dyrkla.

\section{Possible application of iPaD to regenerative medicine}

While the mechanism of aging has been intensively analyzed, how to reverse the aging process is still a difficult challenge to pursue (Negredo et al. 2020). It has been shown that the activation of neurogenesis ameliorates many age-related neurodegenerative disorders, such as Alzheimer's disease and Huntington's disease (Benraiss et al. 2013; Choi et al. 2018; Díaz-Moreno et al. 2018), and our method may offer a new strategy to rejuvenate brain activity for treatment of neurodegenerative disorders. Since Dyrk1a increases amyloid- $\beta$ production (Ryoo et al. 2008), it is possible that $\mathrm{iPaD}$ arrests progression of Alzheimer's disease by inhibiting amyloid- $\beta$ accumulation while replenishing neurons. Conflicting results about neurogenesis in the adult human hippocampus have been reported (Kempermann et al. 2018), yet even if most NSCs are quiescent/dormant in aged humans, our results suggest that such NSCs could be rejuvenated to produce many new neurons continuously, showing the applicability of our strategy to neuronal regeneration technology.

\section{Materials and methods}

Animals

All mice were handled in accordance with the Kyoto University Guide for the Care and Use of Laboratory Animals. The experimental protocols were approved by the Experimental Animal Committee of the Institute for Frontier Life and Medical Sciences, Kyoto University. Wild-type mice (C57BL/6J) were purchased from SLC. Ail4 mice were obtained from Jackson Laboratory.

Lentivirus infection of mice

For screening and neurogenesis induction, $1 \mu \mathrm{L}$ of lentivirus $(3.75$ $\times 10^{5} \mathrm{U} / \mathrm{mL}$ ) was delivered with a flow rate of $0.125 \mu \mathrm{L} / \mathrm{min}$ stereotactically into the dentate gyrus bilaterally with the following coordinates: anteroposterior $=-2.15 \mathrm{~mm}$ from bregma, lateral $= \pm$ $1.85 \mathrm{~mm}$, and ventral $=2.2 \mathrm{~mm}$. For sparse labeling, $1 \mu \mathrm{L}$ of lentivirus $\left(5.0 \times 10^{4} \mathrm{U} / \mathrm{mL}\right)$ was delivered. Brain sections were immunohistologically examined.

Sparse labeling of NSCs

We administered $0.25 \mathrm{~mL}$ of tamoxifen (Tam; $20 \mathrm{mg} / \mathrm{mL}$ in corn oil; Sigma) by oral gavage $5 \mathrm{~d}$ after injection for three consecutive days to activate CreER ${ }^{\mathrm{T} 2}$ activity sparsely in Ai14 mice injected with the control-CreER ${ }^{\mathrm{T} 2}$ or $\mathrm{PPaD}-\mathrm{CreER}^{\mathrm{T} 2}$ lentivirus. Brain sections were examined 1 or $3 \mathrm{wk}$ later. To determine the virus-infected cell types, we first examined control-CreER ${ }^{\mathrm{T} 2}$ lentivirusinfected brains at $1 \mathrm{wk}$ after tamoxifen treatment. We found that $\sim 40 \%$ of tdTomato $^{+}$cells exhibited radial glia-like (RGL) morphology and expressed GFAP and Sox2, indicating that they were quiescent NSCs (Supplemental Fig. S5A, $\mathrm{A}^{\prime \prime}, \mathrm{B}$ ). The other tdTomato $^{+}$cells were mostly isolated single astrocytes (Supplemental Fig. S5A, $\left.\mathrm{A}^{\prime}, \mathrm{C}\right)$. Similarly, at 3 wk after tamoxifen 
treatment, $30 \%-50 \%$ of the tdTomato ${ }^{+}$clones contained RGL cells (Fig. 3B), while the others were isolated single astrocytes. As the Hes 5 promoter is also active in astrocytes, it is likely that those isolated single tdTomato $^{+}$astrocytes were infected directly with the virus rather than differentiating from virus-infected NSCs. Therefore, tdTomato $^{+}$single astrocytes were excluded from the clonal analysis.

\section{Time-lapse imaging of brain slices}

Time-lapse imaging of brain slices was performed as described previously (Sueda et al. 2019). Coronal brain slices (150- $\mu \mathrm{m}$ thickness) were cultured in a medium ( $135 \mathrm{mM} \mathrm{NaCl}_{2}, 5 \mathrm{mM} \mathrm{KCl}, 10$ $\mathrm{mM}$ HEPES, $1 \mathrm{mM} \mathrm{CaCl}_{2}, 1 \mathrm{mM} \mathrm{MgCl} 2,5 \%$ horse serum, $5 \%$ fetal bovine serum) containing $1 \mathrm{mM}$ luciferin at $37^{\circ} \mathrm{C}$ in $5 \% \mathrm{CO}_{2}$ and $80 \% \mathrm{O}_{2}$. Bioluminescence was acquired using a CCD camera (iKon-M DU934P-BV, Andor).

Senescence-associated $\beta$-galactosidase assay

Activity of $\beta$-galactosidase was detected by senescence cell histochemical staining kit (Sigma CS00300). NSCs were cultured in an eight-well chamber (LAB-TEK 154534) with PLO coating. The schedule of lentivirus addition, medium change, and sample fixation was the same as transcriptome analyses. NSCs were fixed by $1 \times$ PFA solution for $7 \mathrm{~min}$. To detect the activity of $\beta$-galactosidase, NSCs were incubated for $3 \mathrm{~h}$ at $37^{\circ} \mathrm{C}$ and reaction was stopped by replacing the reaction mixture with PBS. Twentymonth-old quiescent NSCs and 20-mo-old iPaD NSCs were cultured in the same eight-well chambers but different wells to equalize the reaction condition and incubation period. To quantify $\beta$-galactosidase-positive cell number, three people who did not know about the experiment counted the mCherry and $\beta$-galactosidase-positive cells manually.

\section{Western blot}

Western blot was performed as describe previouslyd (Kobayashi et al. 2019). NSCs in a 12-well plate were collected by plastic cell scraper and lysed by RIPA buffer with protease inhibitor cocktail (Merk 11697498001) for $30 \mathrm{~min}$ at $4^{\circ} \mathrm{C}$. Protein concentrations of total cell lysates were measured by the DC protein assay, and $5 \mu \mathrm{g}$ of protein from each sample was loaded for SDSPAGE. Western blots were visualized by chemiluminescence using Amersham ECL (GE Healthcare) or ECL prime (GE Healthcare), quantified on an LAS3000 image analyzer (Fujifilm), and normalized against the corresponding intensity of $\alpha$-Actin. The following primary antibodies were used for Western blotting: rabbit anti-Actin (Sigma), rabbit anti-p16INK4a (Abcam), and rabbit anti-p19ARF (Abcam). Secondary antibodies were HRP-conjugated antirabbit antibody (GE Healthcare).

\section{RNA in situ hybridization}

RNA in situ hybridization was performed using a digoxigenin-labeled Ascl1 antisense RNA probe, as described previously (Imayoshi et al. 2013).

Other detailed experimental procedures are in the Supplemental Material.

\section{Competing interest statement}

A national (Japanese) patent application (2021-033464) has been filed by Kyoto University.

\section{Acknowledgments}

We thank Caroline Vissers and Karan Ishii for critical reading, and Hongkui Zeng for Ail4 mice. This work was supported by Core Research for Evolutional Science and Technology (JP20gm1110002 to R.K.); the Program for Technological Innovation of Regenerative Medicine (JP19bm0704020 to I.I.); Precursory Research for Innovative Medical Care (JP20gm6410006 to T. Kobayashi) from Japan Agency for Medical Research and Development; Grant-in-Aid for Scientific Research on Innovative Areas (16H06480 to R.K., and 16H06529 to I.I.) and Specially Promoted Research (21H04976 to R.K.) from the Ministry of Education, Culture, Sports, Science, and Technology (MEXT), Japan; and Grant-in-Aid for Scientific Research (B) from Japan Society for the Promotion of Science (20H03260 to T. Kobayashi).

Author contributions: T. Kaise performed the experiments, analyzed the data, and wrote the manuscript. M.F. performed in vitro screening. R.S. performed Ascll expression analysis. W.P. and T. Kobayashi examined chromatin accessibility. M.Y. and I.I. analyzed the data. R.K. designed and supervised the project and wrote the manuscript.

\section{References}

Ables JL, Decarolis NA, Johnson MA, Rivera PD, Gao Z, Cooper DC, Radtke F, Hsieh J, Eisch AJ. 2010. Notch1 is required for maintenance of the reservoir of adult hippocampal stem cells. I Neurosci 30: 10484-10492. doi:10.1523/JNEUROSCI.472109.2010

Adnani L, Dixit R, Chen X, Balakrishnan A, Modi H, Touahri Y, Logan C, Schuurmans C. 2018. Plag1 and Plag12 have overlapping and distinct functions in telencephalic development. Biol Open 7: bio038661. doi:10.1242/bio.038661

Andersen J, Urbán N, Achimastou A, Ito A, Simic M, Ullom K, Martynoga B, Lebel M, Göritz C, Frisén J, et al. 2014. A transcriptional mechanism integrating inputs from extracellular signals to activate hippocampal stem cells. Neuron 83: 1085-1097. doi:10.1016/j.neuron.2014.08.004

Arron JR, Winslow MM, Polleri A, Chang C-P, Wu H, Gao X, Neilson JR, Chen L, Heit JJ, Kim SK, et al. 2006. NFAT dysregulation by increased dosage of DSCR1 and DYRK1A on chromosome 21. Nature 441: 595-600. doi:10.1038/nature04678

Artegiani B, Lindemann D, Calegari F. 2011. Overexpression of cdk4 and cyclinD1 triggers greater expansion of neural stem cells in the adult mouse brain. I Exp Med 208: 937-948. doi:10.1084/jem.20102167

Artegiani B, Lyubimova A, Muraro M, van Es JH, van Oudenaarden A, Clevers H. 2017. A single-cell RNA sequencing study reveals cellular and molecular dynamics of the hippocampal neurogenic niche. Cell Rep 21: 3271-3284. doi:10.1016/j .celrep.2017.11.050

Basak O, Giachino C, Fiorini E, Macdonald HR, Taylor V. 2012. Neurogenic subventricular zone stem/progenitor cells are Notch1-dependent in their active but not quiescent state. $I$ Neurosci 32: 5654-5666. doi:10.1523/JNEUROSCI.0455-12 .2012

Bast L, Calzolari F, Strasser MK, Hasenauer J, Theis FJ, Ninkovic J, Marr C. 2018. Increasing neural stem cell division asymmetry and quiescence are predicted to contribute to the age-related decline in neurogenesis. Cell Rep 25: 3231-3240.e8. doi:10 .1016/j.celrep.2018.11.088

Benraiss A, Toner MJ, Xu Q, Bruel-Jungerman E, Rogers EH, Wang F, Economides AN, Davidson BL, Kageyama R, Nedergaard M, et al. 2013. Sustained mobilization of endogenous neural 
progenitors delays disease progression in a transgenic model of Huntington's disease. Cell Stem Cell 12: 787-799. doi:10 .1016/j.stem.2013.04.014

Berdugo-Vega G, Arias-Gil G, López-Fernández A, Artegiani B, Wasielewska JM, Lee C-C, Lippert MT, Kempermann G, Takagaki K, Calegari F. 2020. Increasing neurogenesis refines hippocampal activity rejuvenating navigational learning strategies and contextual memory throughout life. Nat Commun 11: 135. doi:10.1038/s41467-019-14026-z

Berg DA, Su Y, Jimenez-Cyrus D, Patel A, Huang N, Morizet D, Lee S, Shah R, Ringeling FR, Jain R, et al. 2019. A common embryonic origin of stem cells drives developmental and adult neurogenesis. Cell 177: 654-668.e15. doi:10.1016/j.cell.2019 .02 .010

Blomfield IM, Rocamonde B, Masdeu MDM, Mulugeta E, Vaga S, van den Berg DL, Huillard E, Guillemot F, Urbán N. 2019. Id4 promotes the elimination of the pro-activation factor Ascll to maintain quiescence of adult hippocampal stem cells. Elife 8: e48561. doi:10.7554/eLife.48561

Bonaguidi MA, Wheeler MA, Shapiro JS, Stadel RP, Sun GJ, Ming G, Song H. 2011. In vivo clonal analysis reveals self-renewing and multipotent adult neural stem cell characteristics. Cell 145: 1142-1155. doi:10.1016/j.cell.2011.05.024

Choi SH, Bylykbashi E, Chatila ZK, Lee SW, Pulli B, Clemenson GD, Kim E, Rompala A, Oram MK, Asselin C, et al. 2018. Combined adult neurogenesis and BDNF mimic exercise effects on cognition in an Alzheimer's mouse model. Science 361: eaan8821. doi:10.1126/science.aan 8821

Clark RE, Zola SM, Squire LR. 2000. Impaired recognition memory in rats after damage to the hippocampus. J Neurosci 20: 8853-8860. doi:10.1523/JNEUROSCI.20-23-08853.2000

Díaz-Moreno M, Armenteros T, Gradari S, Hortigüela R, GarcíaCorzo L, Fontán-Lozano Á, Trejo JL, Mira H. 2018. Noggin rescues age-related stem cell loss in the brain of senescent mice with neurodegenerative pathology. Proc Natl Acad Sci 115: 11625-11630. doi:10.1073/pnas.1813205115

Dulken BW, Leeman DS, Boutet SC, Hebestreit K, Brunet A. 2017. Singlecell transcriptomic analysis defines heterogeneity and transcriptional dynamics in the adult neural stem cell lineage. Cell Rep 18: 777-790. doi:10.1016/j.celrep.2016.12.060

Ehm O, Göritz C, Covic M, Schäffner I, Schwarz TJ, Karaca E, Kempkes B, Kremmer E, Pfrieger FW, Espinosa L, et al. 2010. RBPJк-dependent signaling is essential for long-term maintenance of neural stem cells in the adult hippocampus. I Neurosci 30: 13794-13807. doi:10.1523/JNEUROSCI.1567-10.2010

Encinas JM, Michurina TV, Peunova N, Park J-H, Tordo J, Peterson DA, Fishell G, Koulakov A, Enikolopov G. 2011. Divisioncoupled astrocytic differentiation and age-related depletion of neural stem cells in the adult hippocampus. Cell Stem Cell 8: 566-579. doi:10.1016/j.stem.2011.03.010

Engler A, Rolando C, Giachino C, Saotome I, Erni A, Brien C, Zhang R, Zimber-Strobl U, Radtke F, Artavanis-Tsakonas S, et al. 2018. Notch2 signaling maintains NSC quiescence in the murine ventricular-subventricular zone. Cell Rep 22: 992-1002. doi:10.1016/j.celrep.2017.12.094

Fellmann C, Hoffmann T, Sridhar V, Hopfgartner B, Muhar M, Roth M, Lai DY, Barbosa IAM, Kwon JS, Guan Y, et al. 2013. An optimized microRNA backbone for effective single-copy RNAi. Cell Rep 5: 1704-1713. doi:10.1016/j.celrep.2013.11 .020

Fotaki V, Dierssen M, Alcántara S, Martínez S, Martí E, Casas C, Visa J, Soriano E, Estivill X, Arbonés ML. 2002. Dyrk1A haploinsufficiency affects viability and causes developmental delay and abnormal brain morphology in mice. Mol Cell Biol 22: 6636-6647. doi:10.1128/MCB.22.18.6636-6647.2002
Franceschi C, Garagnani P, Gensous N, Bacalini MG, Conte M, Salvioli S. 2019. Accelerated bio-cognitive aging in Down syndrome: state of the art and possible deceleration strategies. $\mathrm{Ag}$ ing Cell 18: e12903. doi:10.1111/acel.12903

Gage FH, Temple S. 2013. Neural stem cells: generating and regenerating the brain. Neuron 80: 588-601. doi:10.1016/j .neuron.2013.10.037

Gonçalves JT, Schafer ST, Gage FH. 2016. Adult neurogenesis in the hippocampus: from stem cells to behavior. Cell 167: 897914. doi:10.1016/j.cell.2016.10.021

Harris L, Rigo P, Stiehl T, Gaber Z, Austin SHL, Masdeu MdM, Edwards A, Urbán N, Marciniak-Czochra A, Guillemot F. 2021. Coordinated changes in cellular behavior ensure the lifelong maintenance of the hippocampal stem cell population. Cell Stem Cell 28: 863-876.e6. doi:10.1016/j.stem.2021 .01 .003

Hensen K, Van valckenborgh ICC, Kas K, Van de Ven WJM, Voz ML. 2002. The tumorigenic diversity of the three PLAG family members is associated with different DNA binding capacities. Cancer Res 62: 1510-1517.

Hochgerner H, Zeisel A, Lönnerberg P, Linnarsson S. 2018. Conserved properties of dentate gyrus neurogenesis across postnatal development revealed by single-cell RNA sequencing. Nat Neurosci 21: 290-299. doi:10.1038/s41593-017-0056-2

Imayoshi I, Sakamoto M, Ohtsuka T, Takao K, Miyakawa T, Yamaguchi $M$, Mori K, Ikeda T, Itohara S, Kageyama R. 2008. Roles of continuous neurogenesis in the structural and functional integrity of the adult forebrain. Nat Neurosci 11: 1153-1161. doi:10.1038/nn.2185

Imayoshi I, Sakamoto M, Yamaguchi M, Mori K, Kageyama R. 2010. Essential roles of notch signaling in maintenance of neural stem cells in developing and adult brains. J Neurosci 30: 3489-3498. doi:10.1523/JNEUROSCI.4987-09.2010

Imayoshi I, Isomura A, Harima Y, Kawaguchi K, Kori H, Miyachi H, Fujiwara TK, Ishidate F, Kageyama R. 2013. Oscillatory control of factors determining multipotency and fate in mouse neural progenitors. Science 342: 1203-1208. doi:10.1126/sci ence. 1242366

Jang M-H, Bonaguidi MA, Kitabatake Y, Sun J, Song J, Kang E, Jun H, Zhong C, Su Y, Guo JU, et al. 2013. Secreted Frizzled-related protein 3 regulates activitydependent adult hippocampal neurogenesis. Cell Stem Cell 12: 215-223. doi:10.1016/j stem.2012.11.021

Kalamakis G, Brüne D, Ravichandran S, Bolz J, Fan W, Ziebell F, Stiehl T, Catalá-Martinez F, Kupke J, Zhao S, et al. 2019. Quiescence modulates stem cell maintenance and regenerative capacity in the aging brain. Cell 176: 1407-1419.e14. doi:10 $.1016 /$ j.cell.2019.01.040

Kempermann G, Gage FH, Aigner L, Song H, Curtis MA, Thuret S, Kuhn HG, Jessberger S, Frankland PW, Cameron HA, et al. 2018. Human adult neurogenesis: evidence and remaining questions. Cell Stem Cell 23: 25-30. doi:10.1016/j.stem.2018 .04 .004

Kobayashi T, Piao W, Takamura T, Kori H, Miyachi H, Kitano S, Iwamoto Y, Yamada M, Imayoshi I, Shioda S, et al. 2019. Enhanced lysosomal degradation maintains the quiescent state of neural stem cells. Nat Commun 10: 5446. doi:10.1038/ s41467-019-13203-4

Lagace DC, Whitman MC, Noonan MA, Ables JL, DeCarolis NA, Arguello AA, Donovan MH, Fischer SJ, Farnbauch LA, Beech RD, et al. 2007. Dynamic contribution of nestin-expressing stem cells to adult neurogenesis. I Neurosci 27: 1262312629. doi:10.1523/JNEUROSCI.3812-07.2007

Leeman DS, Hebestreit K, Ruetz T, Webb AE, McKay A, Pollina EA, Dulken BW, Zhao X, Yeo RW, Ho TT, et al. 2018. 
Lysosome activation clears aggregates and enhances quiescent neural stem cell activation during aging. Science 359: 1277-1283. doi:10.1126/science.aag3048

Lepousez G, Nissant A, Lledo P-M. 2015. Adult neurogenesis and the future of the rejuvenating brain circuits. Neuron 86: 387401. doi:10.1016/j.neuron.2015.01.002

Lie D-C, Colamarino SA, Song H-J, Désiré L, Mira H, Consiglio A, Lein ES, Jessberger S, Lansford H, Dearie A, et al. 2005. Wnt signalling regulates adult hippocampal neurogenesis. Nature 437: 1370-1375. doi:10.1038/nature04108

Llorens-Bobadilla E, Zhao S, Baser A, Saiz-Castro G, Zwadlo K, Martin-Villalba A. 2015. Single-cell transcriptomics reveals a population of dormant neural stem cells that become activated upon brain injury. Cell Stem Cell 17: 329-340. doi:10 $.1016 /$ j.stem.2015.07.002

Lugert S, Basak O, Knuckles P, Haussler U, Fabel K, Götz M, Haas CA, Kempermann G, Taylor V, Giachino C. 2010. Quiescent and active hippocampal neural stem cells with distinct morphologies respond selectively to physiological and pathological stimuli and aging. Cell Stem Cell 6: 445-456. doi:10 $.1016 /$ j.stem.2010.03.017

Madisen L, Zwingman TA, Sunkin SM, Oh SW, Zariwala HA, Gu H, Ng LL, Palmiter RD, Hawrylycz MJ, Jones AR, et al. 2010. A robust and high-throughput Cre reporting and characterization system for the whole mouse brain. Nat Neurosci 13: 133-140. doi:10.1038/nn.2467

Martynoga B, Mateo JL, Zhou B, Andersen J, Achimastou A, Urbán $\mathrm{N}$, van den Berg D, Georgopoulou D, Hadjur S, Wittbrodt J, et al. 2013. Epigenomic enhancer annotation reveals a key role for NFIX in neural stem cell quiescence. Genes Dev 27: 1769-1786. doi:10.1101/gad.216804.113

Miller SM, Sahay A. 2019. Functions of adult-born neurons in hippocampal memory interference and indexing. Nat Neurosci 22: 1565-1575. doi:10.1038/s41593-019-0484-2

Mira H, Andreu Z, Suh H, Lie DC, Jessberger S, Consiglio A, Emeterio JS, Hortigüela R, Marqués-Torrejón MÁ, Nakashima K, et al. 2010. Signaling through BMPR-IA regulates quiescence and long-term activity of neural stem cells in the adult hippocampus. Cell Stem Cell 7: 78-89. doi:10.1016/j .stem.2010.04.016

Molofsky AV, Slutsky SG, Joseph NM, He S, Pardal R, Krishnamurthy J, Sharpless NE, Morrison SJ. 2006. Increasing $p 16^{I N K 4 a}$ expression decreases forebrain progenitors and neurogenesis during ageing. Nature 443: 448-452. doi:10.1038/ nature 05091

Negredo PN, Yeo RW, Brunet A. 2020. Aging and rejuvenation of neural stem cells and their niches. Cell Stem Cell 27: 202-223. doi:10.1016/j.stem.2020.07.002

Nishino J, Kim I, Chada K, Morrison SJ. 2008. Hmga2 promotes neural stem cell self-renewal in young but not old mice by reducing p16 $6^{\text {Ink4a }}$ and p19 Arf expression. Cell 135: 227-239. doi:10.1016/j.cell.2008.09.017

Nyfeler Y, Kirch RD, Mantei N, Leone DP, Radtke F, Suter U, Taylor V. 2005. Jagged1 signals in the postnatal subventricular zone are required for neural stem cell self-renewal. EMBO I 24: 3504-3515. doi:10.1038/sj.emboj.7600816
Pilz G-A, Bottes S, Betizeau M, Jörg DJ, Carta S, Simons BD, Helmchen F, Jessberger S. 2018. Live imaging of neurogenesis in the adult mouse hippocampus. Science 359: 658-662. doi:10.1126/science.aao5056

Ryoo S-R, Cho H-J, Lee H-W, Jeong HK, Radnaabazar C, Kim Y-S, Kim M-J, Son M-Y, Seo H, Chung S-H, et al. 2008. Dual-specificity tyrosine(Y)-phosphorylation regulated kinase 1A-mediated phosphorylation of amyloid precursor protein: evidence for a functional link between Down syndrome and Alzheimer's disease. I Neurochem 104: 1333-1344. doi:10.1111/ j.1471-4159.2007.05075.x

Seib DRM, Corsini NS, Ellwanger K, Plaas C, Mateos A, Pitzer C, Niehrs C, Celikel T, Martin-Villalba A. 2013. Loss of Dickkopf-1 restores neurogenesis in old age and counteracts cognitive decline. Cell Stem Cell 12: 204-214. doi:10.1016/j.stem .2012 .11 .010

Seri B, García-Verdugo JM, McEwen BS, Alvarez-Buylla A. 2001. Astrocytes give rise to new neurons in the adult mammalian hippocampus. I Neurosci 21: 7153-7160. doi:10.1523/JNEUR OSCI.21-18-07153.2001

Shin J, Berg DA, Zhu Y, Shin JY, Song J, Bonaguidi MA, Enikolopov G, Nauen DW, Christian KM, Ming G, et al. 2015. Singlecell RNA-seq with waterfall reveals molecular cascades underlying adult neurogenesis. Cell Stem Cell 17: 360-372. doi:10.1016/j.stem.2015.07.013

Shoji H, Miyakawa T. 2019. Age-related behavioral changes from young to old age in male mice of a C57BL/6J strain maintained under a genetic stability program. Neuropsychopharmacol Rep 39: 100-118. doi:10.1002/npr2.12052

Sueda R, Imayoshi I, Harima Y, Kageyama R. 2019. High Hes1 expression and resultant Ascll suppression regulate quiescent vs. active neural stem cells in the adult mouse brain. Genes Dev 33: 511-523. doi:10.1101/gad.323196.118

Urbán N, van den Berg DL, Forget A, Andersen J, Demmers JA, Hunt C, Ayrault O, Guillemot F. 2016. Return to quiescence of murine neural stem cells by degradation of a pro-activation protein. Science 353: 292-295. doi:10.1126/science.aaf4802

Urbán N, Blomfield IM, Guillemot F. 2019. Quiescence of adult mammalian neural stem cells: a highly regulated rest. Neuron 104: 834-848. doi:10.1016/j.neuron.2019.09.026

Varrault A, Dantec C, Le Digarcher A, Chotard L, Bilanges B, Parrinello $\mathrm{H}$, Dubois $\mathrm{E}$, Rialle $\mathrm{S}$, Severac $\mathrm{D}$, Bouschet $\mathrm{T}$, et al. 2017. Identification of Plagl1/Zacl binding sites and target genes establishes its role in the regulation of extracellular matrix genes and the imprinted gene network. Nuc Acids Res 45: 10466-10480. doi:10.1093/nar/gkx672

Zhang R, Boareto M, Engler A, Louvi A, Giachino C, Iber D, Taylor V. 2019. Id4 downstream of Notch2 maintains neural stem cell quiescence in the adult hippocampus. Cell Rep 28: 14851498.e6. doi:10.1016/j.celrep.2019.07.014

Zheng H, Ying H, Wiedemeyer R, Yan H, Quayle SN, Ivanova EV, Paik J-H, Zhang H, Xiao Y, Perry SR, et al. 2010. PLAGL2 regulates Wnt signaling to impede differentiation in neural stem cells and gliomas. Cancer Cell 17: 497-509. doi:10.1016/j.ccr .2010.03.020 


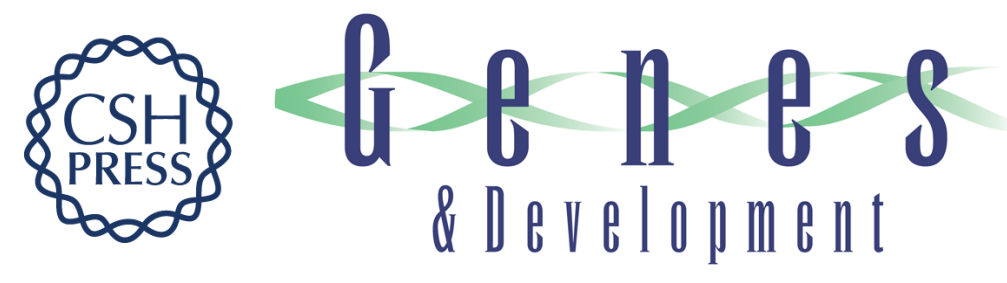

\section{Functional rejuvenation of aged neural stem cells by Plagl2 and anti-Dyrk1a activity}

Takashi Kaise, Masahiro Fukui, Risa Sueda, et al.

Genes Dev. 2022, 36: originally published online December 16, 2021

Access the most recent version at doi:10.1101/gad.349000.121

\section{Supplemental http://genesdev.cshlp.org/content/suppl/2021/12/14/gad.349000.121.DC1 Material}

References This article cites 61 articles, 20 of which can be accessed free at: http://genesdev.cshlp.org/content/36/1-2/23.full.html\#ref-list-1

Creative This article, published in Genes \& Development, is available under a Creative Commons Commons License (Attribution-NonCommercial 4.0 International), as described at License http://creativecommons.org/licenses/by-nc/4.0/.

Email Alerting Receive free email alerts when new articles cite this article - sign up in the box at the top Service right corner of the article or click here.

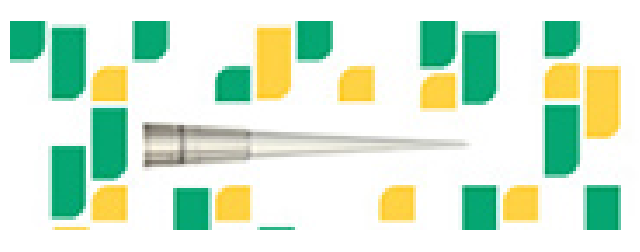

Focused on your science. 